\title{
A model for the rapid assessment of the impact of aviation noise near airports
}

Antonio J. Torija ${ }^{\text {a) }}$, Rod H. Self and Ian H. Flindell

Institute of Sound and Vibration Research, University of Southampton, Highfield, Southampton SO17 1BJ, UK

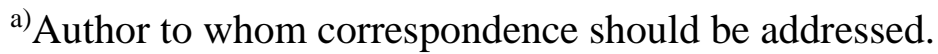

E-mail address: A.J.Martinez@ soton.ac.uk (A.J. Torija) 


\begin{abstract}
This paper introduces a simplified model (Rapid Aviation Noise Evaluator - RANE) for the calculation of aviation noise within the context of multi-disciplinary strategic environmental assessment where input data is both limited and constrained by compatibility requirements against other disciplines. RANE relies upon the concept of noise cylinders around defined flight-tracks with the Noise Radius determined from publicly available Noise-Power-Distance curves rather than the computationally intensive multiple point-to-point grid calculation with subsequent ISOcontour interpolation methods adopted in the FAA's Integrated Noise Model (INM) and similar models. Preliminary results indicate that for simple single runway scenarios, changes in airport noise contour areas can be estimated with minimal uncertainty compared against grid-point calculation methods such as INM. In situations where such outputs are all that is required for preliminary strategic environmental assessment, there are considerable benefits in reduced input data and computation requirements. Further development of the noise-cylinder-based model (such as the incorporation of lateral attenuation, engine-installation-effects or horizontal track dispersion via the assumption of more complex noise surfaces formed around the flight-track) will allow for more complex assessment to be carried out. RANE is intended to be incorporated into technology evaluators for the noise impact assessment of novel aircraft concepts.
\end{abstract}

PACS number(s): 43.50.Lj, 43.50.Rq, 43.50.Sr 


\section{NOMENCLATURE}

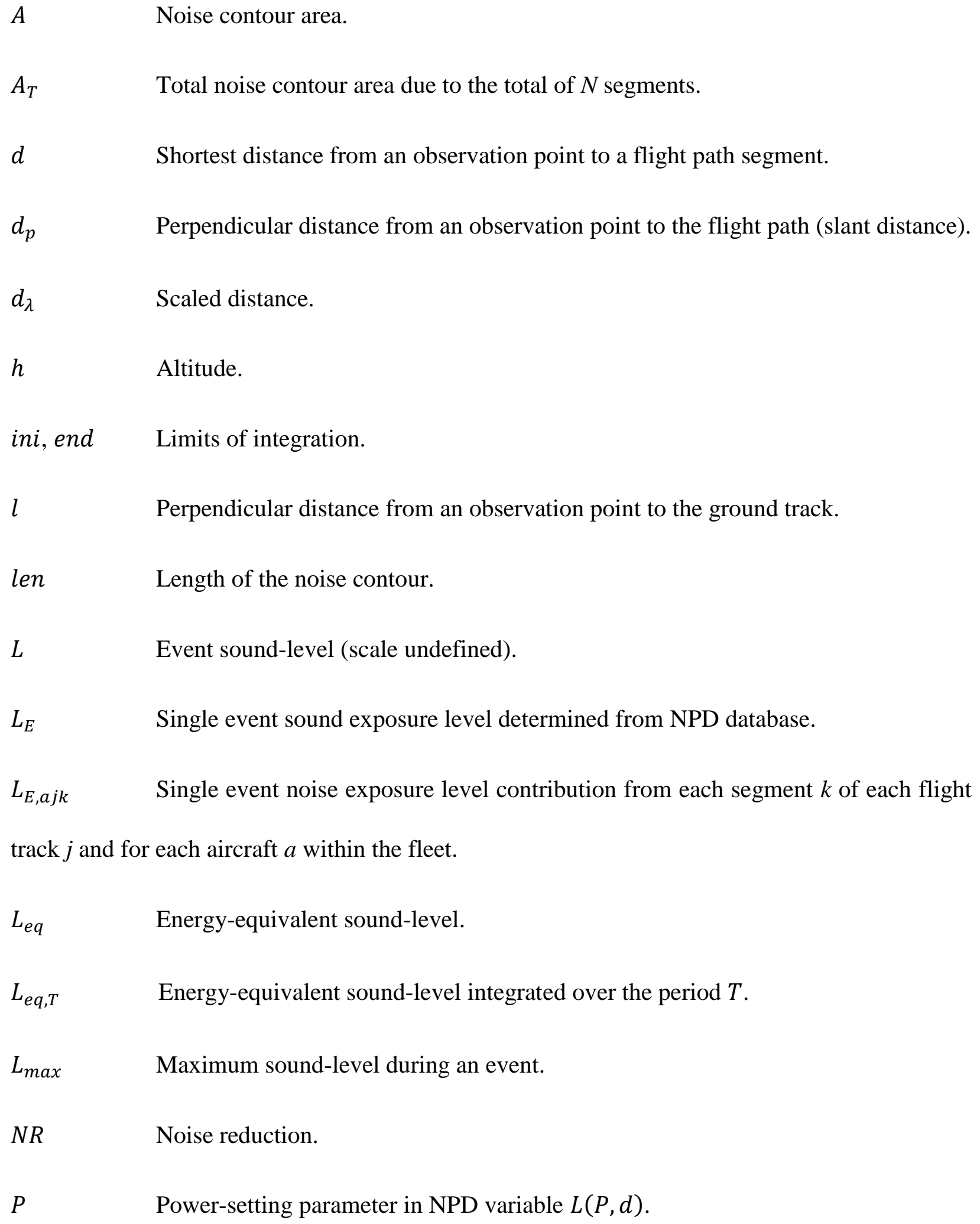


Distance from start of the segment to closest point of approach.

$\mathrm{R}$

$S$

$S$

$T_{0}$

$\mathrm{u}, \mathrm{v}, \mathrm{w}$ segment.

$\mathbf{U}$

$v$

$v_{r e f}$

$\mathcal{W}$
Noise radius.

Segment length.

Orthogonal matrix.

Reference time for integrated sound level

Orthogonal coordinate system with the $\mathrm{u}$ axis is aligned with the $k$ th flightpath

Position vector $(\mathrm{u} \mathrm{v} \mathrm{w})^{\mathrm{T}}$.

Airspeed.

Reference airspeed for which NPD data are defined.

Weighting factor to be applied to the inclination angle $(\gamma)$ of each aircraft in the fleet in order to compute an "equivalent" inclination angle common for the whole aircraft fleet (i.e. average trajectory for the whole fleet).

WP Waypoint.

$\mathrm{x}, \mathrm{y}, \mathrm{z} \quad$ Common orthogonal coordinate system for all $K$ flightpath segments.

$x, y, z \quad$ Orthogonal coordinate system for each $k$ th flightpath segment.

$x$

Position vector $(x y z)^{\mathrm{T}}$.

$\alpha$

Parameter used for calculation of the finite segment correction $\Delta F$.

$\beta \quad$ Elevation angle of aircraft relative to ground plane.

$\gamma \quad$ Inclination angle. 
Depression angle.

Angle of rotation in the horizontal plane.

$\Lambda(\beta, l) \quad$ Lateral attenuation adjustment.

$\Lambda(\beta) \quad$ Long range air-to-ground lateral attenuation

$\Lambda_{y} \quad$ (Orthogonal) rotation matrix.

$\Gamma(l) \quad$ Lateral attenuation distance factor.

$\Delta F \quad$ Finite segment correction.

$\Delta I(\varphi) \quad$ Engine-installation effects adjustment.

$\Delta v \quad$ Duration adjustment.

$\Delta \mathrm{x}, \Delta \mathrm{y} \quad$ Displacement in the $\mathrm{x}$ and $\mathrm{y}$ directions respectively.

$\Delta x \quad$ Displacement in the $x$ dimension as a consequence of the different inclination angles $(\gamma)$.

\section{Subscripts}

$a$

Aircraft.

E $\quad$ End point.

$i$

Start point.

$j$

Flight track.

$k$

Individual flight track segment.

$n \quad$ Common flight track segments for the whole aircraft fleet. 
Number of aircraft movements. 


\section{INTRODUCTION}

The demand for air transportation is projected to experience significant growth over the next few years (DfT, 2013; Eurocontrol, 2013; EASA-EEA-Eurocontrol, 2016). Without appropriate mitigation, any resulting increase in air traffic movements could contribute to increased environmental impacts; such as increased community noise (Kroesen et al., 2008; Bartels et al., 2015; Lawton and Fujiwara, 2016); air quality problems (Khodayari et al., 2014); and climate change (Lee et al., 2009; Hileman et al., 2013; Dessens et al., 2014).

The objective of this paper is to introduce a new aviation noise model - the Rapid Aviation Noise Evaluator (hereinafter called RANE) - intended to support a much more integrated and multi-disciplinary approach to strategic environmental assessment than has been evident in the past. The first stage RANE model described in this paper is capable of estimating aircraft noise contour areas with similar uncertainties to current and much more complex grid-point methods such as the FAA's INM. The main benefit of the new model is the considerable reduction in input data requirements, which providing that the limitations set out below can be accommodated, can facilitate strategic assessment as part of any decision making process, without compromising any more detailed assessment that may be required for regulatory assessment purposes. The reduction in input data can contribute to considerable simplification in multi-disciplinary assessment where there are trade-offs between the different environmental consequences (noise, air quality, and carbon release) of alternative engineering design and air traffic management options. In addition, although this is probably less important nowadays than a few years ago, computation and management overhead requirements can be considerably reduced and this can facilitate the 
strategic comparison of much larger numbers of alternative scenarios and options within the same timescale and budgets than is the case for current grid-point models.

RANE uses the concept of Noise Radius (R) (Zaporozhets et al., 2012) to implement a highly efficient approach for calculating noise contour areas. Using sound-level integration at source, it calculates an "energy-equivalent" Noise Power Distance curve (NPD) for the combination of all the aircraft operations in a given flight path. Based on cylindrical (noise) surfaces formed around the flight path (considered as centreline) and with a given "energy-equivalent" NPD as R, the noise contour area is calculated as the intersection of such cylindrical surface with the ground surface (Stewart and Carson, 1979; 1980). This procedure represents a considerable simplification compared to current high-fidelity (e.g. INM) and some simplified (Bernardo et al., 2015) gridpoint methods which calculate noise contour areas from airport-level noise grids on the basis of logarithmic additions of all the sound-level events occurring during a given flight schedule (see below, and FAA, 2008).

There is a clear need for new simplified models such as RANE if the maximum benefits of engineering noise control (NASA, 2009; ASTS, 2010; EC, 2011; Clean Sky Joint Undertaking, 2012; FAA, 2012; FAA, 2014) and improvements in air traffic management (ATM) and operating procedures (Ky et al., 2009; ASTS, 2010; EU, 2014) are to be realised. In particular, to avoid any further deterioration of the relationships between many airports and surrounding residents the various stakeholders, i.e. manufacturers, airlines, airports and government will be required to address and analyse projections of future aviation scenarios in a more holistic way than hitherto. These analyses will ensure a well-founded evaluation of overall environmental impacts around airports and will require examining a multitude of technology and fleet composition options (considering retirements and market penetrations) and growth rates. For instance, while airframe 
and engine manufacturers have traditionally concentrated on driving down certification noise levels they will increasingly have to consider the benefits of new technology within the fleet operational context. This is especially important in the longer term where highly novel aircraft types will likely require significant changes in both airport and ATM operational procedures.

The available grid-point high-fidelity models, such as INM (FAA, 2008) currently replaced by FAA's Aviation Environmental Design Tool (AEDT) (FAA, 2015), ANCON (Ollerhead et al., 1999), and Nord2000 (Kragh et al., 2001; Ahearn et al., 2012), calculate sound-levels around any airport following standards specified by the European Civil Aviation Conference (ECAC) (2005). As stated by Bernardo et al. (2015), grid-point high fidelity models can require considerable setup effort and high computation time. Full consideration of alternative aviation growth rates, fleet composition and technology improvements in future aircraft implies testing considerable numbers of different scenarios, such that simplified models with considerably reduced input data requirements would be most useful, especially for preliminary strategic planning and decision making procedures. In addition, for strategic environmental assessment it is necessary to consider compatibility against input and output requirements in other disciplines, i.e. environmental (e.g. $\mathrm{CO}_{2}$ and NOx) or economic variables, and any such cross-disciplinary compatibility is not enhanced by the highly detailed approach embodied within grid-point high fidelity models.

Section II of this paper briefly reviews the sound-level calculation procedure used in gridpoint high fidelity models (ECAC, 2005). The analytic basis for noise contour area calculation used by RANE is presented in Section III and this is extended to aircraft fleet problems in Section IV. In Section $\mathrm{V}$ it is presented a brief review of the different metrics used for assessing aviation noise, highlighting the metrics calculated in RANE. Finally, some illustrative results involving 
the application of RANE and the main conclusions reached in this paper are reported in Sections VI and VII together with discussion.

\section{NOISE CALCULATION PROCEDURE IN HIGH-FIDELITY MODELS}

The generic grid-point calculation method standardised in ECAC doc 29 (ECAC, 2005) and used by current high-fidelity airport noise models is briefly described in this section. For the sake of clarity, it should be noted that noise contour is defined as a line of constant value of sound-level (dB) around an airport, and that a noise contour area is defined by the surface inside the boundary of a contour with a given sound-level in its perimeter.

After defining a grid of points with $(\mathrm{x}, \mathrm{y})$ coordinates, current grid-point airport noise models calculate integrated or aggregated sound-levels received at each grid point. Considering a given aircraft $a$ flying along a flight track $j$ with $k$ segments as shown in Fig. 1, the sound-level received at any observation point $(\mathrm{x}, \mathrm{y})$ is calculated from the corresponding NPD data record. The contribution from one flight track segment $k$ to the single event sound exposure level $\left(L_{E}\right)$ at any observation point $(\mathrm{x}, \mathrm{y})$ is calculated as follows (ICAO, 2008):

$$
L_{E, a j k}=L_{E, a j k}(P, d)+\Delta v_{a j k}+\Delta I_{a j k}(\varphi)-\Lambda_{a j k}(\beta, l)-\Delta F_{a j k}
$$

For each aircraft type (and variants), the international aircraft noise and performance database (ANP) tabulates sound-levels (e.g. $\left.L_{E}(P, d)\right)$ as function of propagation distance $d$ - for specific flight configurations (approach, departure, flap settings), and power settings $P$ (ICAO, 2008). Assuming a steady straight flight track at a reference aircraft speed in specified reference atmospheric conditions and in a specified flight configuration (departure or arrival) the NPDs 
define, for a set of power settings $P$ (i.e. corrected net thrust) the resulting sound-levels as a function of distance $d$. Unless the values of $P$ and/or $d$ correspond exactly with the tabulated values of $P$ and/or $d$, a linear interpolation (between tabulated power-settings $P$ ) and a logarithmic interpolation (between tabulated distances $d$ ) must be apply for calculating a given sound-level $L(P, d)(\mathrm{ICAO}, 2008)$

Thus, if $P_{i}$ and $P_{i+1}$ are tabulated power settings in the NPD database for which sound-levels are provided at some set of distances, the sound-level at a given distance for intermediate power $P$, between $P_{i}$ and $P_{i+1}$, is given by:

$$
L(P)=L\left(P_{i}\right)+\frac{L\left(P_{i+1}\right)-L\left(P_{i}\right)}{P_{i+1}-P_{i}} \cdot\left(P-P_{i}\right)
$$

Similarly, if at a given power-setting, $d_{i}$ and $d_{i+1}$ are tabulated distances in the NPD database for which sound-levels are provided, the sound-level for an intermediate distance $d$, between $d_{i}$ and $d_{i+1}$, is given by:

$$
L(d)=L\left(d_{i}\right)+\frac{L\left(d_{i+1}\right)-L\left(d_{i}\right)}{\log _{10}\left(d_{i+1}\right)-\log _{10}\left(d_{i}\right)} \cdot\left(\log _{10}(d)-\log _{10}\left(d_{i}\right)\right)
$$

Using equations (2) and (3), a given sound-level $L(P, d)$ can be calculated for any combination of power-setting $P$ and distance $d$.

However, as observed in equation (1), some caveats must be taken into account:

(i) The NPD curves are defined for a reference aircraft speed. When an aircraft is flying at a different speed there will be a change in the exposure time and consequently results may need to be appropriately adjusted, using duration adjustment $\Delta v$ (see below equation (17)), if time integrated sound-levels are calculated. 
(ii) If the receiver (x,y observation point) is not directly beneath the aircraft flight track, then an engine-installation effects adjustment $(\Delta I(\varphi))$ must be applied. The engine installation causes a non-uniform directionality of sound radiated laterally about the roll axis (line of flight) of the aircraft (i.e. lateral directivity) due to various phenomena of reflection, refraction and scattering by the solid surfaces and aerodynamic flow fields. Also, a lateral attenuation adjustment $(\Lambda(\beta, l))$ must be addressed. At any lateral position off to either side of directly beneath the flight track the sound-level decreases more rapidly with distance than indicated by NPDs. This lateral attenuation is strongly influenced by reflection and refraction effects. Reflections from the ground surface interfere both constructively and destructively (depending on both amplitude and relative phases) with the direct sound, and significant refraction caused by wind and temperature gradients and turbulence attributable to the presence of the surface may also need to be taken into account (ECAC, 2005). Excess lateral attenuation can become significant at low angles of elevation (grazing incidence).

(iii) Each sound-level in the NPD database refers to an aircraft flying along a segment with infinite length in continuous, straight and steady level flight. However, because each segment composing a flight track has finite length, a finite segment correction $(\Delta F)$ must be applied in order to adjust the level to what it would be if the aircraft traversed the finite segment only.

Then, for each point $(\mathrm{x}, \mathrm{y})$ in the grid, the cumulative sound-level is calculated from a logarithmic sum of the sound-levels corresponding to each segment $k$ of each flight track $j$ for each 
aircraft $a$. A given noise contour is determined by interpolation between grid points. More details of the general mathematical formulation of this method is presented in Appendix A.

\section{ANALYTICAL PRINCIPLES FOR NOISE CONTOUR DETERMINATION (SINGLE EVENTS)}

In this section the analytical basis for the calculation of noise contour areas using RANE is presented. Unlike grid-point ECAC doc 29 (ECAC, 2005) based airport noise models, the RANE method does not use multiple point-to-point calculations integrated over the flightpath. RANE uses a more computationally efficient algorithm based on the assumption that the moving aircraft is represented as an axially symmetric noise source, and consequently cylindrical surfaces with constant sound-level are formed around the flight path (Stewart and Carson, 1979). In this paper the aircraft is assumed to represent a moving isotropic noise source for ease of calculation. This is a not unreasonable assumption for current aircraft but an extension to an anisotropic noise source model can be included in future development - this will involve replacing cylinders with some other shape of noise surface around the flight path.

The common central axis of the cylindrical noise surfaces is assumed to be coincident with the flight track axis and the radius of a particular cylindrical noise surface is defined as the $\mathrm{R}$ for a given sound-level. R can be obtained from the NPD database as indicated below (see equation (16)). For a single flight track, the coordinates of the boundaries and areas of a noise contour are defined by the intersection of such cylindrical surfaces with the ground surface (Zaporozhets et al., 2012). For simplicity we will assume this to be flat, but non-flat ground surfaces can also be dealt with geometrically. 
Let us define an orthogonal coordinate system $(\mathrm{u}, \mathrm{v}, \mathrm{w})$, where the $\mathrm{u}$ axis is aligned with the kth flightpath segment (see Fig. 2). Let us also define an orthogonal coordinate system $(x, y, z)$, in which for each $k$ flightpath segment $x$ is the projection of the $\mathrm{u}$ axis on the ground horizontal plane, and $y$ axis is coincident with the $\mathrm{v}$ axis (rotation around $y$ axis) (Fig. 2). Note that, for the kth airborne flightpath segment, the intersection of the extension of the $\mathrm{u}$ axis and the ground horizontal plane is set at the same origin in the coordinate system $(x, y, z)$ (see Section IV.B).

The overall flight track is divided into separate segments, $k=1, \ldots, K$, in each of which the flight parameters are assumed to remain constant. Each segment is characterised by: (1) an inclination angle $\gamma_{k} ;(2)$ an angle of rotation in the horizontal plane $\psi_{k} ;(3)$ the segment length $s_{k}$; (4) the start and end point of the segment ( $x_{k, i}$ and $x_{k, f}$ respectively); and (5) the $\mathrm{R}_{k}$.

For projecting the cylindrical noise surface formed around the flight path (in a given $k$ segment), defined as $\mathbf{U}^{\mathrm{T}} \mathbf{S} \mathbf{U}=\mathrm{R}^{2}$, the $\mathbf{U}=(\mathrm{u} \mathrm{v} \mathrm{w})^{\mathrm{T}}$ position vector must be rotated around the $v$ (or $y$ ) axis, therefore

$$
\boldsymbol{X}^{T} \Lambda_{y} S \Lambda_{y}^{\mathrm{T}} \mathcal{X}=\mathrm{R}^{2}
$$

where $\boldsymbol{X}=\left(\begin{array}{lll}x & y z\end{array}\right)^{\mathrm{T}}$ is the position vector projected on the horizontal plane, and $\boldsymbol{S}$ and $\boldsymbol{\Lambda}_{\boldsymbol{y}}$ (rotation matrix) are orthogonal matrices

$$
\begin{gathered}
\boldsymbol{S}=\left[\begin{array}{lll}
0 & 0 & 0 \\
0 & 1 & 0 \\
0 & 0 & 1
\end{array}\right] \\
\boldsymbol{\Lambda}_{\boldsymbol{y}}=\left[\begin{array}{ccc}
\cos (\gamma) & 0 & -\sin (\gamma) \\
0 & 1 & 0 \\
\sin (\gamma) & 0 & \cos (\gamma)
\end{array}\right]
\end{gathered}
$$


The noise contour will be determined by the intersection of the three-dimensional noise contour in terms of the coordinate system $(x, y, z)$ defined by equation (4) with the ground

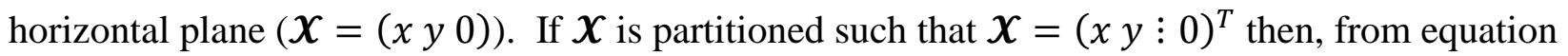

$$
x^{2} \cdot \sin ^{2}(\gamma)+y^{2}=\mathrm{R}^{2}
$$

Equation (5) is the equation for an ellipse and allows the definition of a noise contour (of a flightpath composed of only 1 segment) with only 2 parameters, i.e. $\mathrm{R}$ and $\gamma$.

For a typical 3-D trajectory consisting of $K$ flightpath segments as illustrated in Fig. 1, the noise contour will be composed of contributions due to each of the various $k$ segments. Equation (5) gives the noise contour for each $k$ segment in the coordinate system $(x, y)$. In order to generate the complete noise contour, the contribution of each $k$ segment must be transformed to an orthogonal coordinate system $(\mathrm{x}, \mathrm{y}, \mathrm{z})$, in common with each of the other segments, using a series of rotation (around $\mathrm{z}$ axis) and translation transformations. Thus, recalling that each $k$ flightpath segment is characterised by a given inclination angle $\gamma_{k}$ and angle of rotation in the horizontal plane $\psi_{k}$, then

$$
\left\{\begin{array}{l}
\mathrm{x}=x+\Delta \mathrm{x}_{k} \\
\mathrm{y}=y+\Delta \mathrm{y}_{k}
\end{array}\right.
$$

where $\Delta \mathrm{x}_{k}$ and $\Delta \mathrm{y}_{k}$, the displacement in the $\mathrm{x}$ and $\mathrm{y}$ directions respectively for each $k$ segment, can be defined as

$$
\left\{\begin{array}{l}
\Delta \mathrm{x}_{k}=\sum_{m=1}^{k-1} \cos \left(\psi_{m}\right) \cdot s_{m}-\frac{\cos \left(\psi_{k}\right) \cdot \sum_{m=1}^{k-1} \tan \left(\gamma_{m}\right) \cdot s_{m}}{\tan \left(\gamma_{k}\right)} \\
\Delta \mathrm{y}_{k}=\sum_{m=1}^{k-1} \sin \left(\psi_{m}\right) \cdot s_{m}-\frac{\sin \left(\psi_{k}\right) \cdot \sum_{m=1}^{k-1} \tan \left(\gamma_{m}\right) \cdot s_{m}}{\tan \left(\gamma_{k}\right)}
\end{array}\right.
$$


Therefore, the equation of the noise contour generated by an aircraft flying along the $k$ th segment in terms of the common $(\mathrm{x}, \mathrm{y})$ coordinate system is given by:

$$
\begin{aligned}
\sin ^{2}\left(\gamma_{k}\right) \cdot\left[\left(\mathrm{x}-\Delta \mathrm{x}_{k}\right) \cdot \cos \left(\psi_{k}\right)-\left(\mathrm{y}-\Delta \mathrm{y}_{k}\right) \cdot \sin \left(\psi_{k}\right)\right]^{2} \\
\quad+\left[\left(\mathrm{x}-\Delta \mathrm{x}_{k}\right) \cdot \sin \left(\psi_{k}\right)+\left(\mathrm{y}-\Delta \mathrm{y}_{k}\right) \cdot \cos \left(\psi_{k}\right)\right]^{2}=\mathrm{R}_{k}^{2}
\end{aligned}
$$

For a given value of $\mathrm{x}$, the corresponding value of $\mathrm{y}$ is computed using equation (8). It should be noted that the analytical method describe above, assumes that a given noise contour will be composed of the contributions due to a set of infinite $K$ flightpath segments. Using this approach, for a given choice of $\mathrm{x}$, the parameters in equation (8) correspond to the $k$ segment closest to $\mathrm{x}$. Therefore, because each $k$ flightpath segment is considered to be infinite, the Noise Fraction adjustment (see $\Delta F$ in equation (1) and in appendix A) is not applied.

\section{EXTENSIONS TO THE BASIC METHOD}

\section{A. Extended analytical method for aircraft fleet}

The analytical method presented in Section III allows the calculation of noise contour areas for single events. The operational profile of each aircraft $a$ within an aircraft fleet is defined using a $K+1$ number of waypoints $\left(W P_{k}\right)$. This set of $K+1$ waypoints $\left(W P_{k}\right)$ represents the start and end of each individual $k$ flight path segment. Each $W P_{k}$ waypoint is characterised with a given value of altitude $\left(h_{k}^{\prime}\right)$, airspeed $\left(v_{k}^{\prime}\right)$ and power-setting $\left(P_{k}^{\prime}\right)$. To extend the analytical method for aircraft fleet noise contour area calculation, a common set of $N+1$ waypoints $\left(W P_{n}\right)$ has to be 
defined for the whole aircraft fleet. These $N+1$ waypoints $\left(W P_{n}\right)$ define the start and end of a number of common $N$ segments for the aircraft fleet. For a given aircraft fleet, a waypoint must be defined for each significant change of $h, v$ or $P$ (take-off, initial climb, acceleration and flap retraction, power cutback, continued climb, etc.) in each of the aircraft within the fleet. Also, note that because constant acceleration is assumed, $v$ and $P$ vary linearly with time.

For each $W P_{n}$ waypoint the value of altitude $\left(h_{n}^{\prime}\right)$, airspeed $\left(v_{n}^{\prime}\right)$ and power-setting $\left(P_{n}^{\prime}\right)$ is computed using an iterative process, so while $W P_{k}<W P_{n}<W P_{k+1}$

$$
\begin{gathered}
h_{n}^{\prime}=h_{k}^{\prime}+\left(\frac{\left(W P_{n}-W P_{k}\right) \cdot\left(h_{k+1}^{\prime}-h_{k}^{\prime}\right)}{W P_{k+1}-W P_{k}}\right) \\
P_{n}^{\prime}=\sqrt{P_{k}^{\prime 2}+\frac{W P_{n}-W P_{k}}{W P_{k+1}-W P_{k}} \cdot\left(P_{k+1}^{\prime 2}-P_{k}^{\prime 2}\right)} \\
v_{n}^{\prime}=\sqrt{v_{k}^{\prime 2}+\frac{W P_{n}-W P_{k}}{W P_{k+1}-W P_{k}} \cdot\left(v_{k+1}^{\prime 2}-v_{k}^{\prime 2}\right)}
\end{gathered}
$$

Then, for each $n$ common segment

$$
\begin{gathered}
P_{n}=\sqrt{P_{n}^{\prime 2}+\frac{1}{2} \cdot\left(P_{n+1}^{\prime 2}-P_{n}^{\prime 2}\right)} \\
v_{n}=\sqrt{v_{n}^{\prime 2}+\frac{1}{2} \cdot\left(v_{n+1}^{\prime 2}-v_{n}^{\prime 2}\right)} \\
s_{n}=W P_{n+1}-W P_{n} \\
\gamma_{n}=\tan ^{-1}\left(\frac{h_{n+1}^{\prime}-h_{n}^{\prime}}{s_{n}}\right)
\end{gathered}
$$

where 
$P_{n}, v_{n}, s_{n}$ and $\gamma_{n}$ is the power setting, airspeed, length and inclination angle for each $n$ common segment.

From the power-setting $P_{n}, L\left(P_{n}\right)$ is calculated using equation (2). Once known $P_{n}$ and $v_{n}$ for each common segment $n$, considering $\mathrm{R}=d, \mathrm{R}_{n}$ for the segment $n$ can be determined using a re-arrangement of equation (3). Note that equation (16) includes the duration adjustment $\Delta v_{n}$.

$$
\mathrm{R}_{n}=10\left[\left(\left(\left(L\left(P_{n}, d_{i}\right)+\Delta v_{n}\right)-L(d)\right) \cdot\left(\frac{\log _{10}\left(d_{i+1}\right)-\log _{10}\left(d_{i}\right)}{\left(L\left(P_{n}, d_{i+1}\right)+\Delta v_{n}\right)-\left(L\left(P_{n}, d_{i}\right)+\Delta v_{n}\right)}\right)\right)+\log _{10}\left(d_{i}\right)\right]
$$

where $L(d)$ is the sound-level for which the noise contour area is to be calculated, $L\left(P_{n}, d_{i}\right)$ is the first sound-level greater than $L(d)$ as tabulated in NPD database (for power-setting $P_{n}$ ), $L\left(P_{n}, d_{i+1}\right)$ is the first sound-level smaller than $L(d)$ as tabulated in NPD database (for powersetting $\left.P_{n}\right)$, and $d_{i}$ and $d_{i+1}$ are tabulated distances in NPD database corresponding to $L\left(P_{n}, d_{i}\right)$ and $L\left(P_{n}, d_{i+1}\right)$ respectively. Note that the sound-levels in the NPD database assume the reference airspeed $v_{r e f}(296.32 \mathrm{~km} / \mathrm{h})$. An airspeed higher or lower than $v_{r e f}$ will lead to a lower or higher exposure time respectively, and consequently to a lower or higher time integrated sound-level $\left(L_{E}\right.$ or $\left.L_{e q}\right)$. Then, for calculating time integrated sound-level noise contours, if the actual airspeed in a given $n$ segment $\left(v_{n}\right)$ is different to $v_{r e f}$ a duration adjustment (expressed in $\mathrm{dB}$ ) must be applied.

$$
\Delta v_{n}=10 \cdot \log _{10}\left(\frac{v_{r e f}}{v_{n}}\right)
$$

Also, atmospheric conditions can have very significant impacts on actual noise contour areas. For this reason, for atmospheric conditions other than the SAE-AIR-1845 (SAE, 1986) standard atmosphere, NPD values can be corrected using the procedure explained in (Section 3.4.1 of FAA, 2008). 
For a number of aircraft $a$, with $a=1, \ldots, A$, and a number of operations of each aircraft $m$, with $m=1, \ldots, M$, then for a given distance $d_{i}$, the $L_{e q, T}\left(d_{i}\right)$ (corresponding to the whole aircraft fleet in a specific segment $n$ ) is given by

$$
L_{e q, T, n}\left(d_{i}\right)=10 \cdot \log _{10}\left[\left(\frac{1}{T}\right) \cdot\left(\sum_{a=1}^{A} \sum_{m=1}^{M} 10^{L_{a m}\left(P_{n}, d_{i}\right) / 10}\right)\right]
$$

where $L_{a m}\left(P_{n}, d_{i}\right)$ is the sound-level (obtained from NPD database) emitted by each operation $m$ of a given aircraft $a$ flying along a segment $n$ (with a given power-setting $P_{n}$ and at a given distance $d_{i}$ ), and $T$ is the integration time (where the number of operations $M$ takes place). Then $L\left(P_{n}, d_{i}\right)$ can be replaced by $L_{e q, T, n}\left(d_{i}\right)$ in equation (16) for estimating $\mathrm{R}_{n}$ (corresponding to the whole aircraft fleet). If $L_{e q, T, n}\left(d_{i}\right)$ replaces $L\left(P_{n}, d_{i}\right)$ in equation (16), then an "average NPD set" is computed, such that the NPD represents fleet level $L_{e q, T}$ decibels instead of individual aircraft $L_{E}$ decibels.

A further complication arises when considering a number of aircraft $a$ flying along a given segment $n$ with a different inclination angle $\gamma_{n a}$, an "equivalent" inclination angle $\gamma_{n}$ (common for the whole aircraft fleet) for such segment $n$ can be obtained as follows.

$$
\gamma_{n}=\sum_{a=1}^{A} \gamma_{n a} \cdot \mathcal{W}_{n a}
$$

with

$$
\mathcal{W}_{n a}=\frac{\sum_{m=1}^{M} 10^{\left(L_{a m}\left(P_{n}, d i\right) / 10\right)}}{\sum_{a=1}^{A} \sum_{m=1}^{M} 10^{\left(L_{a m}\left(P_{n}, d i\right) / 10\right)}}
$$

$\mathcal{W}_{n a}$ represents a weighting factor to be applied to the inclination angle $\left(\gamma_{n}\right)$ of each aircraft $a$ in the fleet in order to compute an "equivalent" inclination angle common for the whole aircraft fleet (i.e. average trajectory for the whole fleet). 
It should be noted that, for an extreme case where an aircraft 1 is climbing at an inclination angle $\gamma_{n 1}$ twice the inclination angle $\gamma_{n 2}$ of an aircraft 2, assuming an "equivalent" inclination angle $\gamma_{n}$ (as calculated in equation (19)) common for both aircraft for the estimation of the change in noise contour area achieves a significantly good performance, as compared to INM (see Appendix B).

\section{B. Estimation of noise contour areas}

This section describes the procedure for calculating noise contour areas for a given aircraft fleet, from the calculation of $\mathrm{R}_{n}$ and $\gamma_{n}$ parameters for each $n$ segment in the common flight path. As indicated above, in this paper, a noise contour area is defined as the surface inside the boundary of a contour with $L(d)$ sound-level at its perimeter. For the calculation of the noise contour area corresponding to the whole flight path, the contribution of each $n$ segment must be determined. For calculating the noise contour area, an approximation is made in this paper that the total contour area of a given flight path is the same as if the trajectory is straightened out, i.e. as if the flight path is in only one vertical plane (with all power settings etc. being the same as the original). In order to validate this approximation, the noise contour areas for the metrics 51-, 54- and 57-dBA $L_{e q, 15 h}$ were calculated (using INM) for the straightened out trajectory and for turning angles from $15 \mathrm{deg}$ up to $135 \mathrm{deg}$. Two conditions were simulated: 50 and 75 movements of each aircraft considered in this study (i.e. CRJ-900, 737-800, A330 and 747-400). Although not all the potential scenarios in terms of operational volumes and fleet mixes were tested, this approximation was evaluated for large range of noise contour areas (for a single runway with only departure operations), i.e. from 
$24.4 \mathrm{~km}^{2}$ (57-dBA $L_{e q, 15 h}$ with 50 movements of each aircraft, assuming a straight-out trajectory) to 97.2 $\mathrm{km}^{2}$ (51-dBA $L_{e q, 15 h}$ with 75 movements of each aircraft, assuming a straight-out trajectory). The results (see supplementary material) showed that the error (in noise contour area estimation) made with the straightened out trajectory assumption is in the range $-2.5 \%-+0.7 \%$. Based on these calculations, it can be assumed that the error made with this approximation is negligible in comparison with the total noise contour area.

When the $n$ segment is on the ground $\left(\gamma_{n}=0\right)$, as observed in equation (5), the calculation of the noise contour area $\left(A_{n}\right)$ is only dependant on $\mathrm{R}_{n}$ (and the length of the $n$ segment, $s_{n}$ ). Thus,

$$
A_{1}=2 \cdot \mathrm{R}_{1} \cdot s_{1}+\frac{\pi \cdot \mathrm{R}_{1}^{2}}{2}
$$

If there are more than one segment on the ground, $A_{n}$ for subsequent $n$ segments can be calculated as

$$
A_{n}=2 \cdot \mathrm{R}_{n} \cdot s_{n}
$$

For all airborne $n$ segments, $A_{n}$ contributed by each $n$ segment is obtained from the rearrangement and integration of equation (5).

$$
\begin{gathered}
A_{n}=2 \cdot \int_{\text {ini }_{n}}^{\text {end }} y(x) d x \\
A_{n}=\left[\frac{\mathrm{R}_{n}^{2}}{\sin \left(\gamma_{n}\right)} \cdot \sin ^{-1}\left(\frac{x_{n} \cdot \sin \left(\gamma_{n}\right)}{\mathrm{R}_{n}}\right)+x_{n} \sqrt{\mathrm{R}_{n}^{2}-x_{n}^{2} \cdot \sin ^{2}\left(\gamma_{n}\right)}\right]_{\text {ini }_{n}}^{\text {end }}
\end{gathered}
$$


For the determination of the limits of integration, if it is assumed that the aircraft continues flying the extension of the $n$ segment, then the length of the noise contour $\left(\operatorname{len}_{n}\right)$ can be defined as

$$
\operatorname{len}_{n}=x_{\max }=\frac{\mathrm{R}_{n}}{\sin \left(\gamma_{n}\right)}
$$

Since it was set that the extension of the $n t h$ segment intersects the ground horizontal plane $(z=0)$ at the same origin in the $(x, y, z)$ coordinate system (see Fig. 3$)$, the start $\left(x_{n, i}\right)$ and the end $\left(x_{n, f}\right)$ points of each $n$ segment are

$$
\begin{gathered}
x_{n, i}=\frac{\sum_{m=1}^{n-1} s_{m} \cdot \tan \left(\gamma_{m}\right)}{\tan \left(\gamma_{n}\right)} \\
x_{n, f}=x_{n, i}+s_{n}
\end{gathered}
$$

Note that $\Delta x_{n}$ represents the displacement in the $x$ dimension as a consequence of the different $\gamma_{n}$ inclination angle between each airborne $n$ segment

$$
\Delta x_{n}=\frac{\sum_{m=1}^{n-1} s_{m} \cdot \tan \left(\gamma_{m}\right)}{\tan \left(\gamma_{n}\right)}-x_{n-1, f}
$$

Then, for each $n$ segment $i n i_{n}=x_{n, i}$. If $l e n_{n}>x_{n, f}$, the noise contour is not ended and $\operatorname{end}_{n}=x_{n, f}$, while if $\operatorname{len}_{n}<x_{n, f}$ the noise contour is ended ( $n$ is the last segment) and $e n d_{n}=$ len $n_{n}$. Fig. 3 shows an example of a flight path composed of two segments, and illustrates the definition of each factor for the determination of the limits of integration.

The total noise contour area due to the total of $N$ segments is given by

$$
A_{T}=\sum_{n=1}^{N} A_{n}
$$


The analytical procedure for the noise contour and noise contour area estimation as showed above is defined for departure problems. However, it should be noted that approach problems can be easily solved by transforming then into an equivalent departure problem (i.e. inverting the order of the aircraft flightpath segments).

\section{AVIATION NOISE METRICS CALCULATED IN RANE}

The NPD curves database provides for a number of single event noise metrics, i.e. metrics describing the noise occurring during one single noise event (e.g. an aircraft over-flight). Based on the noy scale, and with the application of a tone-correction, NPD curves are provided for the maximum tone-corrected perceived noise level (PNLTM) and for the effective perceived noise level (EPNL), where the noise energy is integrated over a time period of 10s. EPNL is the metric used for noise certification purposes. Also, NPD curves are provided for other two metrics where the spectrum sound-level is corrected with the A-weighting frequency filter: maximum sound level $\left(L_{\max }\right)$ and sound exposure level $\left(L_{E}\right)$, where the noise energy of an aircraft noise event is integrated over a time period of $1 \mathrm{~s}$. These corrections applied to the spectrum sound-level are aimed at accounting for the relative loudness perceived by the human ear (Torija et al., 2016).

Overall noise impact around airports is usually assessed using exposure metrics which describe average noise exposure experienced over defined time periods (Jones and Cadoux, 2009). The most widely used time averaged exposure metric is the energy-equivalent sound-level $\left(L_{e q, T}\right)$. The areas and numbers of residents within defined $L_{e q, T}$ noise contours can be calculated for any given airport and operating scenario from aircraft flight track and air traffic movement data. The 
$57 \mathrm{dBA}-L_{e q, 16 h}$ contour has been adopted by the UK Government to define the approximate onset of significant community annoyance around airports (Jones and Cadoux, 2009). Although there is no technical difficulty in setting up the algorithms to calculate any other noise exposure metric, RANE stage 1 has accordingly been optimised to determine either $L_{E}$ or $L_{e q, T}$ contour areas. The $L_{e q, T}$ corresponding to the whole aircraft fleet can be calculated from the $L_{E}$ of each individual aircraft $a$, considering the number of movements $M$ that occur during the period of time $T$, as indicated in equation (18).

EPNL and $L_{E}$ metrics differ in the filtering applied to the spectrum sound-level (EPNL gives greater subjective emphasis to spectrum content at frequencies above $1 \mathrm{kHz}$ ) and in that EPNL computation requires the application of an arbitrary tone-correction penalty for prominent tonal content. The mathematical relationship between EPNL and $L_{E}$ metrics varies depending on the frequency spectrum, but arithmetic difference tends to be fairly consistent across a wide range of current aircraft types (3-5 dB) (Jones and Cadoux, 2009). Exploring the NPD database, for a wide range of current aircraft (and especially for the most recent types), and within the distances between the flight path and the different certification points, equivalent changes in $L_{E}$ and EPNL were observed when increasing the net thrust (see supplementary material). For these reasons, in this paper, sound level differences in EPNdB are assumed to be equivalent to sound level differences in $\mathrm{dB}\left(L_{E}\right.$ or $\left.L_{e q, T}\right)$.

\section{RESULTS}




\section{A. Benchmarking}

To assess the capability of RANE stage 1 for estimating changes in noise contour area for individual events, RANE was compared against INM using four different aircraft, one for each aircraft category as suggested by ICAO Independent Expert Panel (IEP2) (Adib et al., 2014):

(i) Regional Jet: Bombardier CRJ-900

(ii) Small/Medium Range Twin: Boeing 737-800

(iii) Long Range Twin: Airbus A330

(iv) Long Range Quad: Boeing 747-400

The benchmarking consists of estimating the change in noise contour area $\left(\Delta A_{T, i}\right)$ :

$$
\Delta A_{T, i}=\frac{\left(A_{T, i}-A_{T, r e f}\right)}{A_{T, r e f}}
$$

between a reference scenario with noise contour area $A_{T, \text { ref }}$ and the altered scenario with noise contour area $A_{T, i}$.

The change of noise contour area when an increased number of operations for each aircraft type is considered. Thus, for each aircraft type, the $57 \mathrm{dBA}-L_{e q, 16 h}$ noise contour area was estimated, using both INM and RANE, where the number of operations was multiplied by a factor F from 1 to 3. Fig. 4 (a-d) shows the relative 57 dBA-LAeq,d noise contour area as referred to $\mathrm{F}=1$ (see equation (29)) for CRJ-900, 737-800, A330 and 747-400 aircraft respectively. As observed in Fig. 4 (a-d), the differences between RANE and INM were less than $1 \%$ for all cases. 
The developed analytical method, and the assumptions of "equivalent" inclination angle and "equivalent" fleet-level NPD were also validated for a number of fleet composition scenarios. Assuming a baseline scenario of 25 movements of each aircraft considered in this study (i.e. CRJ900, 737-800, A330 and 747-400), the change in 54dBA- 57dBA- and 60dBA- $L_{e q, 16 h}$ contour areas was calculated using INM and RANE for changes in aircraft movements from 25 to 125 (Table I). As shown in Table I, the differences between RANE and INM were in the range -3.6\% $-+4.2 \%$ for $54 \mathrm{dBA}-L_{e q, 16 h}$ contour area, $-2.9 \%-+0.0 \%$ for $57 \mathrm{dBA}-L_{e q, 16 h}$ contour area and $0.9 \%-+5.4 \%$ for $60 \mathrm{dBA}-L_{e q, 16 h}$ contour area. If assumed that there is no change in the spatial distribution of flight tracks, with variations in aircraft fleet, the changes in noise contours are at first order independent from changes in shape, and therefore, only changes in noise contour area take place. To validade this assumption, for each fleet composition scenario showed in Table I, the $L_{e q, 16 h}$ values were computed in a grid of $250 \times 250 \mathrm{~m}$ using INM and RANE (applying engineinstallation effects and lateral attenuation adjustments as shown in Appendix A) using the approximations and simplifications assumed in the analytical method of RANE. In this grid calculation it was found that the correlation coefficients $\left(\mathrm{R}^{2}\right)$ between INM and RANE computed $L_{e q, 16 h}$ values were about 0.99 for all the scenarios considered (see supplementary material).

The capability of the new method for estimating the change in noise contour area for a whole aircraft fleet was also assessed. The overall fleet of Gatwick airport in 2013 (Lee et al., 2013) (Table II) and the aviation growth rates for the period 2010-2055 as projected in 2013 by the Department for Transport in UK (DfT, 2013) (Table III) were used for comparing INM and RANE to calculate changes in 57dBA-LAeq,d noise contour area, referred to year 2013 (see equation (31)). As observed in Fig. 5, RANE is able to estimate the change in the 57dBA-L $\mathrm{L}_{\text {Aeq,d }}$ contour 
area for the projected increase in the number of operations between the period 2013-2055 with no differences compared to INM exceeding $0.3 \%$.

These results show that the analytical method presented in this paper is able to replicate a high-fidelity doc 29 (ECAC, 2005) based model (INM) in the estimation of the change of noise contour areas with variations in the overall aircraft fleet to within minimal uncertainty.

\section{B. Illustrative case-study: Forecast of change in noise contour area with the introduction of noise reduction technology}

Agencies and organisations involved in the evaluation and management of environmental impact of aviation, and specifically noise impact around airports, require tools for assessing the potential variations in aviation noise impact for future scenarios, where an increase in the number of operations is projected (DfT, 2013; Eurocontrol, 2013; EASA-EEA-Eurocontrol, 2016) and also taking into account fleet replacement by new aircraft with different noise reduction technologies. Moreover, the aviation industry needs tools to strategically assess (at an early stage in the design process) how different technology platforms are likely to perform in terms of aviation noise and other environmental impacts. Hitherto, such analyses have centred on individual aircraft event noise as compared to an assessment within a more realistic whole airport assessment. RANE is able to undertake such tasks, offering the different stakeholders valuable information for the assessment and forecast of overall aviation noise impact.

As an illustrative case-study, changes in overall $57 \mathrm{dBA}-L_{e q, 16 h}$ noise contour area were estimated for a range of future aviation growth scenarios in the UK, assuming that any increases 
in noise due to increased traffic would be offset by incremental replacement of the current aircraft fleet by new quieter aircraft generations. The following assumptions were made:

(i) The number of operations per day in the year 2010 for the whole UK was used as the basis for the estimation (SA, 2013).

(ii) Increases in the total numbers of operations between the period 2010-2050 were assumed according to the projections made by DfT (2013).

(iii) It was assumed that two new generations of aircraft types (G1 and G2 respectively) would be introduced. Table IV shows the EIS and the period for the transition to be completed for each aircraft category (SA, 2013).

(iv) Due to the introduction of new noise reduction technologies, a given noise reduction at each certification point (lateral, flyover and approach) for each aircraft category and for generations G1 and G2 was assumed (Table V). It should be noted that, as mentioned above, noise reductions in EPNdB are assumed to be equivalent to noise reductions in $\mathrm{dB}$, and so the values in EPNdB shown in Table $\mathrm{V}$ were used for producing the $L_{e q, 16 h}$ equivalent fleet-level NPDs for G1 and G2 aircraft. The noise reductions in $\mathrm{dB}$ assumed for generation $\mathrm{G} 1$ were based on the differences in sound levels at each certification point between the G1 sound levels proposed by SA (SA, 2013) and the sound levels of the reference aircraft (Adib et al., 2014). The noise reductions in $\mathrm{dB}$ at each certification point for each aircraft category proposed by ICAO IEP2 (Adib et al., 2014) for year 2030 were used as a basis for the estimation of the $\mathrm{dB}$ reduction of each generation $\mathrm{G} 2$ aircraft category, considering the actual EIS as suggested by SA (SA, 2013). In this work, for each record of the NPD 
database, the $L(P, d)$ for future (G1 and G2) aircraft generations was computing by subtracting the corresponding noise reduction shown in Table V from the soundlevel for the same power setting $(P)$ and distance $(d)$ as tabulated in the NPD database record of the corresponding current aircraft used as reference for a particular aircraft type category. The noise reduction at the approach certification point was used for computing the approach NPD records for G1 and G2 aircraft. A special case takes place for departure NPD records. For departure operations, noise reductions are projected for lateral (full power) and flyover (reduced power after power cut-off) certification points. Thus, for power setting above and below the power cut-off value the noise reduction at the lateral and at the flyover certification points respectively were used for computing the departure NPD records for G1 and G2 aircraft. Fig. 6 shows an example of the departure NPDs for the reference small/medium range twin aircraft of the current generation, i.e. 737-800 with engine CF567B (left) and for the corresponding G2 aircraft with the noise reductions as projected by Adib et al. (2014) (right).

This procedure for computing NPDs of G1 and G2 aircraft is based on the assumption that the aircraft is a lumped source, where a given noise reduction takes place without spectral changes, whereas, in practice, acoustic propagation through the atmosphere is affected by differences in frequency spectrum at the source. This procedure is aimed at correcting the NPDs for matching the noise reduction projected at each certification point. Of course, new aircraft concepts, with noise reduction technologies affecting individual aircraft sources differently, will have a different balance (in acoustical dominance) of individual sources, and therefore 
spectral composition, at the different stages of departure and approach operations. For this reason, RANE is being developed to be coupled with technology evaluators, which will provide NPD records for novel aircraft concepts, in order to assess their potential benefit in terms of noise impact reduction. Moreover, novel aircraft concepts are likely to have non-conventional directivity patterns. RANE would be able to account for such directivity patterns by replacing the cylindrical surfaces with the corresponding quadratic or other surfaces.

Changes in 57dBA-L $\mathrm{L}_{\text {Aeq,d }}$ noise contour areas (reference to year 2010) for the period 20202050 under the assumptions mentioned above are shown in Fig. 7. According to the results shown in Fig. 7, the introduction of new noise reduction technologies in aircraft generations G1 and G2 would be able to offset, in terms of noise contour areas, the projected increase in the number of operations. For instance, in year 2050, even with an increase of $90 \%$ in the number of operations the total $57 \mathrm{dBA}-\mathrm{L}_{\text {Aeq, }}$ noise contour area could be reduced by almost $20 \%$. On the other hand, it can also be observed that a higher reduction of the $57 \mathrm{dBA}-\mathrm{L}_{\text {Aeq,d }}$ noise contour area for departure operations could be achieved (as compared to approach operations) due to the greater projected $\mathrm{dB}$ reduction at lateral and flyover certification points (as compared to approach certification point). It should be noted, of course, that changes in overall noise contour areas do not necessarily correlate with changes in overall impacts measured by the number of residents exposed within the defined noise contours, because these numbers also depend on any changes in the overall shape of the contours in relation to the geographical distributions of residents in areas around airport. 


\section{VII.CONCLUSIONS}

This paper introduces a new airport noise calculation model, RANE, based on fast, flexible and computationally efficient analytical methods. In its current version, RANE stage 1 is able to accurately estimate changes in noise contour areas for variations in aircraft fleet (number and composition). Assuming that there is no change in the spatial distribution of flight tracks, with variations in aircraft fleet, the changes in noise contours are at first order independent from changes in shape, and therefore, only changes in noise contour area take place. This assumption has been validated with the results presented in the supplementary material. RANE uses the concept of noise radius R. From the calculation of an "energy-equivalent" NPD (sound-level integration at source) for the combination of all aircraft operations along a given flight path, a specific noise contour area is calculated as the intersection of a cylindrical surface assumed to be formed around the flight path (with $\mathrm{R}$ as cylinder radius) with the ground surface. For the test cases evaluated in this paper, RANE was able to estimate changes in airport noise contour areas with minimal uncertainty compared against grid-point calculation methods such as INM.

RANE stage 1 has been developed for supporting multi-disciplinary strategic aviation environmental assessment studies. Wherever at early stages in decision processes, multidisciplinary strategic environmental assessment studies do not require contour shape information, the analytical method (on which RANE is based) presented in this paper allow replication of the shape of the noise contour for simple single runway scenarios (see supplementary material), with considerably reduced input data requirements as compared to conventional grid-point models. This allows users to either use publically available input data and/or make and justify simple input 
data assumptions, and because of its calculation strategy, a reduced number of individual calculations, as compared to grid-point high-fidelity models, are required for computing noise outputs. One important simplification is that the analytical method used in RANE stage 1 assumes that a given noise contour will be composed of the contributions due to a set of infinite $K$ flightpath segments, and therefore, does not require the application of the Noise Fraction adjustment (see $\Delta F$ in equation (1) and appendix A). With this simplification, and under the conditions studied in this paper, changes in noise contour areas and grid-point sound-levels (see supplementary material) have been computed with minimum uncertainty as compared to high-fidelity airport noise models. Moreover, since based on flexible analytical methods, novel exposure metrics can be incorporated in RANE, in order to enhance the noise impact assessment of aviation. For instance, changes in noise contour areas might be computed assuming a given penalty to the number of operations above a given threshold. All the above are important requirements of aviation noise models to be incorporated in multi-disciplinary strategic environmental assessment tools, because of the high number of scenarios to be evaluated and because input data is both limited and constrained by compatibility requirements against the other disciplines.

The current version of RANE can be used by different stakeholders for addressing aircraft noise issues at national or regional level. For example, RANE can be used for estimating changes in aviation noise impact with variations in aircraft fleet composition, i.e., what would be the variation of the noise contour area if a given new aircraft is introduced in the fleet or if a current aircraft category is replaced by a quieter one, or what would be the variation of the noise contour area if different aviation growth rates and noise reduction rates are assumed for different aircraft categories within the fleet. Moreover, changes in noise contour areas as consequence of aircraft operational changes $(\Delta \gamma, \Delta \mathrm{R})$ can be estimated. Also, RANE is being developed to be coupled with 
technology evaluators, which will provide NPD records for novel aircraft concepts, so that it can be used by the aviation industry to contribute to policy decisions about which future technology platforms would be likely to be the most environmentally efficient when considered holistically.

In this work, lateral attenuation and lateral directivity factors were not considered. These factors can be significant at low elevation angles, i.e. on the initial portion of the flightpath (generally within the boundaries of airports). Exploratory analysis shows that lateral attenuation and lateral directivity factors can be included in the definition of the noise radius $\mathrm{R}$ as a function of inclination angle $\gamma$. It is likely that novel aircraft concept will have non-conventional directivity patterns. In this sense, the cylindrical surfaces considered in this work can be replaced by any quadratic surface in order to model such non-conventional directivity patterns.

The current version of RANE is restricted to single runway scenarios, and only considers vertical dispersion in the flight track (see Section IV.A). The technical approach implemented in RANE based on noise cylinders (or other quadratic surface) requires further development where assessment of more complex situations which include other airport layouts (e.g. multiple runways, crossing runways, etc.) and multiple flight paths are required. Further work is being carried out to overcome these limitations, so RANE stage 2 can be applied to airport-specific cases, computing complex noise contours and taking into account the geographic distributions of resident populations around airports. 


\section{ACKNOWLEDGMENTS}

This work was partly supported by the Engineering and Physical Science Research Council (grant number EP/M026868/1). 


\section{APPENDIX A: Summary of ECAC doc 29 formulation for sound-level calculation}

Recalling equation (1):

$L_{E}(P, d)$ is the sound exposure level interpolated from the NPD to correspond with the power setting $\mathrm{P}$ and distance $\mathrm{d}$ relevant to the particular airplane flight segment and ground location (assuming segment with infinite length).

$\Delta v$ is the duration adjustment (see equation (17)).

$\Delta I(\varphi)$ is the engine-installation effects (lateral directivity) adjustment. The lateral directivity is significantly influenced by the location of the engine, so a different adjustment should be applied to underwing- and fuselage-mounted engines, as indicated below (ECAC, 2005):

$$
\Delta I(\varphi)=10 \cdot \log _{10}\left(\frac{\left(a \cdot \cos ^{2}(\varphi)+\sin ^{2}(\varphi)\right)^{b}}{c \cdot \sin ^{2}(\varphi)+\cos ^{2}(2 \cdot \varphi)}\right)
$$

where,

$\varphi$ is the depression angle.

For wing-mounted engines, $\mathrm{a}=0.00384, \mathrm{~b}=0.0621, \mathrm{c}=0.878$.

For fuselage-mounted engines, $\mathrm{a}=0.1225, \mathrm{~b}=0.03290, \mathrm{c}=1$.

It should be noted that $\Delta I(\varphi)=0$ for propeller aircraft.

$\Lambda(\beta, l)$ is the lateral attenuation adjustment. Assuming that lateral attenuation depends on (i) elevation angle $\beta$ measured in the vertical plane and (ii) lateral displacement from the aircraft 
ground track $l$, an empirical approximation adapted from AIR-5662 (SAE, 2006) can be used for calculating $\Lambda(\beta, l)$.

$$
\Lambda(\beta, l)=\Gamma(l) \cdot \Lambda(\beta)
$$

where the distance factor $\Gamma(l)$ is given by

$$
\begin{gathered}
\Gamma(l)=1.089 \cdot\left(1-e^{-0.00274 \cdot l}\right) \quad \text { for } 0 \leq l \leq 914 m \\
\Gamma(l)=1 \quad \text { for } l>914 m
\end{gathered}
$$

And the long-range air-to-ground lateral attenuation $\Lambda(\beta)$ is given by

$$
\begin{gathered}
\Lambda(\beta)=1.137-0.0229 \cdot \beta+9.72 \cdot e^{(-0.142 \cdot \beta)} \quad \text { for } 0 \leq \beta \leq 50 \\
\Lambda(\beta)=0 \quad \text { for } 50 \leq \beta \leq 90
\end{gathered}
$$

$\Delta F$ is the finite segment correction, which account for the finite length of the segment. This energy fraction factor is based on the sound radiation of a "fourth-power" 90-degree dipole sound source (FAA, 2008). The finite segment correction is define as follows (ICAO, 2008):

$$
\Delta F=10 \cdot \log _{10}(F)
$$

where $F$ is the energy fraction term, which multiply by the noise exposure from the whole infinite segment results in the noise exposure produced at the observer position $(\mathbf{O})$ from a flight path segment $\mathbf{C}_{1} \mathbf{C}_{2}$ (with a start-point $\mathbf{C}_{1}$, an end-point $\mathbf{C}_{2}$, and $\mathbf{C}_{\mathbf{p}}$ as the position in the flight path segment perpendicular to $\mathbf{O})$.

$$
F=\frac{1}{\pi}\left(\frac{\alpha_{2}}{1+\alpha_{2}^{2}}+\tan ^{-1}\left(\alpha_{2}\right)-\frac{\alpha_{1}}{1+\alpha_{1}^{2}}-\tan ^{-1}\left(\alpha_{1}\right)\right)
$$

with 


$$
\begin{gathered}
\alpha_{1}=-\frac{q}{d_{\lambda}} \\
\alpha_{2}=-\frac{q-s}{d_{\lambda}} \\
d_{\lambda}=d_{0} \cdot 10^{\left[L_{E}\left(P, d_{p}\right)-L_{\max }\left(P, d_{p}\right)\right] / 10} \\
d_{0}=\frac{2}{\pi} \cdot v_{r e f} \cdot t_{0}
\end{gathered}
$$

where,

$d_{p}$ is the perpendicular distance between observer $\mathbf{O}$ and segment (minimum slant range).

$s$ is the length of the flight track segment.

$q$ is the distance from $\mathbf{C}_{\mathbf{1}}$ to $\mathbf{C}_{\mathbf{p}}$.

$d_{\lambda}$ is called "scaled distance". Because NPD data are derived empirically from actual aircraft noise measurements, some internal inconsistencies could take place in the calculation of noise contours (for instance, for $L_{E}$ or $L_{\max }$ descriptors). For this reason, the so-called scaled distance must be used for $F$ calculation, instead of $d_{p}$.

It should be noted that $t_{0}$ denotes a reference time $\left(t_{0}=1\right.$ for $\left.L_{E}\right)$.

The cumulative energy-equivalent sound-level $L_{e q}$ at any receiver with coordinates $(\mathrm{x}, \mathrm{y})$ is calculated as follows:

$$
\left.L_{e q}(\mathrm{x}, \mathrm{y})=10 \cdot \log _{10}\left(\frac{1}{T_{0}} \cdot \sum_{a} \sum_{j} \sum_{k} 10^{\left(L_{E, a j k}(\mathrm{x}, \mathrm{y}) / 10\right.}\right)\right)
$$

where

$T_{0}$ is the reference time period 
$L_{E, a j k}(\mathrm{x}, \mathrm{y})$ is the single event noise exposure level contribution from each segment $k$ of each flight track $j$ and for each aircraft $a$ within the fleet.

\section{APPENDIX B: Validation of the "equivalent" common inclination angle $\left(\gamma_{n}\right)$ assumption}

From the inclination angle of each aircraft $\left(\gamma_{n a}\right)$, an "equivalent" common inclination angle for the whole aircraft fleet $\left(\gamma_{n}\right)$ is obtained using equation (19). In order to assess the viability of this simplification for estimating changes in noise contour areas (for an aircraft fleet), the error associated with the "equivalent" common inclination angle was evaluated via a simple case-study. In this case-study, a flight path composed of only 1 segment was defined. Five aircraft were selected and assumed to fly along such 1 segment flight path: (1) B747400 (reference aircraft) as representative of the long range quad category climbing with an inclination angle of 7.5 degrees; (2) CRJ900 (regional jet category), (3) A320 (small/medium range twin category, small size), (4) B737800 (small/medium range twin category, large size) and (5) A330 (long range twin category) climbing with an inclination angle of 15 degrees. Four combinations were evaluated with two aircraft types flying along the 1 segment flight path, i.e. the reference aircraft $\left(\gamma_{n a}=7.5\right.$ degrees $)$ plus each of the other four aircraft $\left(\gamma_{n a}=15\right.$ degrees $)$. For each combination, four conditions were assumed:

(i) Ref: $1 \times$ Reference aircraft $+1 \times$ Aircraft with $\gamma_{n a}=15$ degrees.

(ii) Sc1: $2 \times$ Reference aircraft $+1 \times$ Aircraft with $\gamma_{n a}=15$ degrees.

(iii) Sc2: $1 \times$ Reference aircraft $+2 \times$ Aircraft with $\gamma_{n a}=15$ degrees.

(iv) Sc3: $2 \times$ Reference aircraft $+2 \times$ Aircraft with $\gamma_{n a}=15$ degrees. 
For all the evaluated conditions, the change in $90-L_{E}$ contour area (as compared to the 90 $L_{E}$ contour area for the Ref condition) was estimated using INM (each aircraft climbing at the corresponding inclination angle, i.e. 7.5 and 15 degrees) and RANE (the two aircraft types climbing at the "equivalent" inclination angle calculated using equation (19)) (Table BI). 
Adib, M., Catalano, F., Hileman, J., Huff, D., Ito, T., Joselzon, A., Khaletskiy, Y., Michel, U., Mongeau, L., Tester, B.J. (2014). Novel aircraft noise technology review and medium and long term noise reduction goals, Report to CAEP by the CAEP Noise Technology Independent Expert Panel (IEP2), ICAO Doc 10017, Montréal, Canada. Available at: http://www.icao.int/publications/Documents/10017_cons_en.pdf [retrieved Mar 2015].

Aeronautics Science and Technology Subcommittee (ASTS) of the Committee on Technology (COT) of the National Science and Technology Council (NSTC) (2010). National aeronautics research and development plan (biennial update), Washington, D.C. Available at: http://www.whitehouse.gov/sites/default/files/microsites/ostp/aero-rdplan-2010.pdf [retrieved May 2015].

Ahearn, M.J., Boeker, E.R., Rosenbaum, J.E., Gerbi, P.J., Roof, C.J. (2012). The Analysis of Modeling Aircraft Noise with the Nord2000 Noise Model, CreateSpace Independent Publ., Cambridge, MA, Chaps. 1-3.

Bartels, S., Márki, F., Müller, U. (2015). “The influence of acoustical and non-acoustical factors on short-term annoyance due to aircraft noise in the field - The COSMA study," Sci. Total Environ. 538, 834-843.

Bernardo, J.E., Kirby, M., Mavris, D. (2015). "Development of a rapid fleet-level noise computation model," J. Aircraft 52, 721-733. 
Clean Sky Joint Undertaking (2012). Clean Sky at a glance: Bringing sustainable air transport closer, Brussels. Available at: http://ec.europa.eu/research/jti/pdf/cleansky_at_a_glance.pdf [retrieved May 2015].

Department for Transport (DfT) (2013). UK aviation forecast. Available at: https://www.gov.uk/government/uploads/system/uploads/attachment_data/file/223839/aviationforecasts.pdf [retrieved Feb 2015].

Dessens, O., Köhler, M.O., Rogers, H.L., Jones, R.L., Pyle, J.A. (2014). “Aviation and climate change," Transp. Policy 34, 14-20.

Eurocontrol (2013). Challenges of growth, Task 7: European air traffic in 2050. Available at: https://www.eurocontrol.int/sites/default/files/article/content/documents/officialdocuments/reports/201306-challenges-of-growth-2013-task-7.pdf [retrieved Feb 2015].

European Civil Aviation Conference (ECAC) (2005). Report on standard method of computing noise contours around civil airports. ECAC.CEAC Doc 29, 3rd ed., vol 2: Technical guide, Paris, France. Available at: https://www.ecac-ceac.org/documents/10189/51566/DOC29-Vol2Technical+Guide-3rd_edition-e.pdf/db599b49-e0fb-4f58-a28e-29e3591b0533. 
European Commission (EC) (2011). Flightpath 2050: Europe's vision for aviation. Luxembourg. Available at: http://ec.europa.eu/transport/modes/air/doc/flightpath2050.pdf [retrieved May 2015].

European Environment Agency (EEA), European Aviation Safety Agency (EASA) and Eurocontrol (2016). European aviation environmental report. Available at: http://ec.europa.eu/transport/modes/air/aviation-strategy/documents/european-aviationenvironmental-report-2016-72dpi.pdf [retrieved Feb 2016].

European Union (EU) (2014). Regulation 598/2014 of the European Parliament and the Council of 16 April 2014 on the establishment of rules and procedures with regard to the introduction of noise related operating restrictions at Union airport within a balanced approach and repealing Directive 2002/30/EC (OJ L 173, 12.6.2014, p. 65-78).

Federal Aviation Administration (FAA) (2008). Integrated Noise Model (INM) Version 7.0 Technical Manual, Rept. FAA-AEE-08-01, Washington, D.C. Available at: https://www.faa.gov/about/office_org/headquarters_offices/apl/research/models/inm_model/inm 7_0d/media/INM_7.0_Technical_Manual.pdf [retrieved Jan. 2015].

Federal Aviation Administration (FAA) (2012). Portfolio of goals, FY 2011 methodology report, FAA flight plan performance measures, Washington, D.C. Available at: http://www.faa.gov/about/plans_reports/media/FY11\%20Portfolio\%20of\%20Goals.pdf [retrieved May 2015]. 
Federal Aviation Administration (FAA) (2014). Continuous lower emissions, energy, and noise (CLEEN) program, Washington, A.C. Available at: https://www.faa.gov/about/office_org/headquarters_offices/apl/research/aircraft_technology/clee n [retrieved May 2015].

Federal Aviation Administration (FAA) (2015). Aviation Environmental Design Tool (AEDT) Version $2 b \quad$ User Guide, Washington, D.C. Available at: https://aedt.faa.gov/Documents/UserGuide.pdf [retrieved Sept. 2015].

Hileman, J.I., De la Rosa Blanco, E., Bonnefoy, P.A., Carter, N.A. (2013) “The carbon dioxide challenge facing aviation,” Prog. Aerosp. Sci. 63, 84-95.

International Civil Aviation Organization (ICAO) (2008). Recommended method for computing noise contours around airport, DOC 9911, Montréal, Canada.

Jones, K., Cadoux, R. (2009). Metrics for aircraft noise, ERCD Report 0904, London, UK. Available at: http://publicapps.caa.co.uk/docs/33/ERCD0904.pdf [retrieved May. 2015].

Khodayari, A., Olsen, S.C., Wuebbles, D.J. (2014). "Evaluation of aviation NOx-induced radiative forcings for 2005 and 2050,” Atmos. Environ. 91, 95-103. 
Kragh, J., Plovising, B., Storeheier, S.A., Jonasson, H.G. (2001). Nordic Environmental Noise Prediction Methods, Nord 2000, Summary Report, General Nordic Sound Propagation Model and Applications in Source-Related Prediction Methods," Acoustics and Vibrations, Danish Electronics, Light \& Acoustics, Lyngby, Denmark. Available at: http://share.madebydelta.com/wpcontent/publications/akustik/paper_og_rapport/Nordic_Environmental_Noise_Prediction_Metho ds_Nord2000_Summary_Report_-_Prediction_Methods.pdf [retrieved Jun 2015].

Kroesen, M., Molin, E.J.E., van Wee, B. (2008). "Testing a theory of aircraft noise annoyance: a structural equation analysis," J. Acoust. Soc. Am. 123(6), 4250-4260.

Ky, P., Schoeffmann, E., Platteau, E. (2009). Delivering green results - A summary of European AIRE project results in 2009. SESAR Joint Undertaking, Brussels. Available at: http://www.sesarju.eu/sites/default/files/AIRE_Executive_Summary.pdf [retrieved November 2016].

Lawton, R.N., Fujiwara, D. (2016). "Living with aircraft noise: Airport proximity, aviation noise and subjective wellbeing in England," Transport. Res. D-TR E 42, 104-118.

Lee, D.S., Fahey, D.W., Forster, P.M., Newton, P.J., Wit, R.C., Lim, L.L., Owen, B., Sausen, R. (2009). "Aviation and global climate change in the $21^{\text {st }}$ century," Atmos. Environ. 43(22), 35203537. 
Lee, J., Cebrian, G., Edmonds, L., Patel, J., Weston, E. (2013). Noise exposure contours for Gatwick airport 2013, Environmental Research and Consultancy Dept., U.K. Civil Aviation Authority, Rept. 1402, London. Available at: https://www.gov.uk/government/uploads/system/uploads/attachment_data/file/363233/LGW_20 13_report.pdf [retrieved Jul 2015].

NASA (2009). Environmentally responsible aviation project: Integrated systems research program. Available at: http://www.aeronautics.nasa.gov/isrp/era [retrieved June 2015].

Ollerhead, B.J., Rhodes, D.P., Viinikainen, M.S., Monkman, D.J., Woodley, A.C. (1999). The UK Civil Aircraft Noise Contour Model ANCON: Improvements in Version 2, Environmental Research and Consultancy Dept., U.K. Civil Aviation Authority, Rept. 9842, London. Available at: http://www.caa.co.uk/docs/33/ercd9842.pdf [retrieved Jan 2015].

Stewart, E.C., Carson, T.M. (1979). A closed-form solution for noise contours, NASA Technical Paper 1432, Washington, D. C. Available at: http://ntrs.nasa.gov/archive/nasa/casi.ntrs.nasa.gov/19800003620.pdf [retrieved Mar 2015].

Stewart, E.C., Carson, T.M. (1980). "Simple method for prediction of aircraft noise contours," J. Aircraft 17, 828-830.

Society of Automotive Engineers (SAE), Committee A-21, Aircraft Noise (1986). Procedure for the computation of airplane noise in the vicinity of airports, Aerospace Information Report No. 1845. 
Society of Automotive Engineers (SAE) International (2006). Prediction method for lateral attenuation of airplane noise during take-off and landing, AIR-5662.

Sustainable Aviation (SA) (2013). The SA noise road-map: A blueprint for managing noise from aviation sources to 2050. Available at: http://www.sustainableaviation.co.uk/wpcontent/uploads/SA-Noise-Roadmap-Publication-version1.pdf [retrieved Aug 2014].

Torija, A.J., Flindell, I.H., Self, R.H. (2016). "Subjective dominance as a basis for selecting frequency weightings", J. Acoust. Soc. Am. 140(2), 843-854.

Atmos. Environ. 43(22), 3520-3537.

Zaporozhets, O., Tokarev, V., Attenborough, K. (2012). Aircraft Noise: Assessment, prediction and control, Taylor \& Francis ed., Boca Raton (FL), USA. 


\section{Tables/figure captions}

\section{TABLE I}

Error of RANE model as compared to INM when changes in noise contour areas (compared to baseline scenario of 25 movements of each aircraft considered) are computed for a number of aircraft fleet compositions (aircraft movements changing from 25 to 125 ). In brackets it is shown the noise contour are as calculated with INM.

\begin{tabular}{llll}
\hline \hline Number of Operations & $54 \mathrm{dBA}-L_{e q, 15 h}$ & $57 \mathrm{dBA}-L_{e q, 15 h}$ & $60 \mathrm{dBA}-L_{e q, 15 h}$ \\
$(\mathrm{CRJ}-900 / 737-800 / \mathrm{A} 330 / 747-400)$ & & & \\
\hline$(50 / 50 / 50 / 50)$ & $-1.0 \%(42.5)$ & $0.3 \%(24.5)$ & $2.5 \%(14.0)$ \\
$(75 / 75 / 75 / 75)$ & $-1.9 \%(58.5)$ & $-0.2 \%(33.7)$ & $3.3 \%(19.4)$ \\
$(100 / 100 / 100 / 100)$ & $-2.2 \%(72.9)$ & $-0.7 \%(42.6)$ & $2.9 \%(24.5)$ \\
$(125 / 125 / 125 / 125)$ & $-1.6 \%(86.3)$ & $-1.0 \%(50.9)$ & $2.5 \%(29.3)$ \\
$(50 / 25 / 25 / 25)$ & $1.2 \%(25.8)$ & $1.7 \%(14.8)$ & $1.4 \%(8.5)$ \\
$(75 / 25 / 25 / 25)$ & $2.4 \%(27.2)$ & $2.7 \%(15.6)$ & $3.0 \%(8.9)$ \\
$(100 / 25 / 25 / 25)$ & $3.4 \%(28.5)$ & $4.1 \%(16.4)$ & $4.0 \%(9.3)$ \\
$(125 / 25 / 25 / 25)$ & $4.2 \%(29.8)$ & $5.0 \%(17.2)$ & $4.5 \%(9.8)$ \\
$(25 / 50 / 25 / 25)$ & $0.2 \%(28.7)$ & $1.2 \%(16.4)$ & $2.1 \%(9.4)$ \\
$(25 / 75 / 25 / 25)$ & $0.1 \%(33.0)$ & $2.2 \%(18.8)$ & $3.1 \%(10.8)$ \\
$(25 / 100 / 25 / 25)$ & $0.2 \%(37.2)$ & $2.4 \%(21.2)$ & $4.1 \%(12.1)$ \\
$(25 / 125 / 25 / 25)$ & $-0.4 \%(41.5)$ & $2.7 \%(23.4)$ & $5.4 \%(13.4)$ \\
$(25 / 25 / 50 / 25)$ & $-0.1 \%(28.6)$ & $0.7 \%(16.4)$ & $2.3 \%(9.5)$ \\
$(25 / 25 / 75 / 25)$ & $-0.4 \%(32.5)$ & $1.0 \%(18.8)$ & $2.9 \%(10.8)$ \\
$(25 / 25 / 100 / 25)$ & $-0.4 \%(36.2)$ & $1.2 \%(21.2)$ & $3.6 \%(12.1)$ \\
$(25 / 25 / 125 / 25)$ & $-0.8 \%(39.9)$ & $0.9 \%(23.4)$ & $3.2 \%(13.4)$ \\
$(25 / 25 / 25 / 50)$ & $-1.9 \%(33.4)$ & $-1.0 \%(19.1)$ & $-0.9 \%(10.9)$ \\
$(25 / 25 / 25 / 75)$ & $-3.5 \%(41.8)$ & $-2.5 \%(24.1)$ & $-0.4 \%(13.7)$ \\
$(25 / 25 / 25 / 100)$ & $-3.6 \%(57.7)$ & $-2.9 \%(33.1)$ & $-0.3 \%(18.8)$ \\
$(25 / 25 / 25 / 125)$ & & & \\
\hline \hline & & & \\
& & & \\
& & &
\end{tabular}




\section{TABLE II}

Average number of summer day operations in Gatwick airport for year 2013 (Lee et al., 2013).

\begin{tabular}{lll}
\hline \hline Aircraft & Code & Number of Operations \\
\hline Airbus A319-131/V2522-A5 & A319-131 & 248.50 \\
Airbus A320-211/CFM56-5A1 & A320-211 & 95.70 \\
Airbus A320-232/V2527-A5 & A320-232 & 10.00 \\
Airbus A321-232/IAE V2530-A5 & A321-232 & 26.70 \\
Airbus A330-343/RR TRENT 772B & A330RR & 11.50 \\
Boeing 737-400/CFM56-3C-1 & B737400 & 86.00 \\
Boeing 737-800/CFM56-7B26 & B737800 & 84.20 \\
Boeing 747-400/PW4056 & B747400 & 8.40 \\
Boeing 757-200/RB211-535E4 & B757RR & 24.80 \\
Boeing 767-400ER/CF6-80C2B(F) & B767400 & 7.70 \\
Boeing 777-200ER/GE90-90B & B777200 & 20.00 \\
DASH 8-300/PW123 & DASH-8 & 31.70 \\
Embraer 170/190 (GV) & EMB-170/190 & 31.10 \\
\hline
\end{tabular}


TABLE III

Aviation growth rates for the UK as projected by DfT (2013).

\begin{tabular}{ll}
\hline \hline Period & Growth Rate $(\%)$ \\
\hline $2011-2015$ & $0,80 \%$ \\
$2016-2020$ & $1,83 \%$ \\
$2021-2025$ & $2,00 \%$ \\
$2026-2030$ & $1,64 \%$ \\
$2031-2035$ & $1,70 \%$ \\
$2036-2040$ & $1,64 \%$ \\
$2041-2045$ & $1,86 \%$ \\
$2046-2050$ & $1,34 \%$ \\
$2051-2055$ & $1,34 \%$ \\
\hline \hline
\end{tabular}




\section{TABLE IV}

Entry into service date (EIS) and period to complete the introduction of aircraft generations G1 and G2 for each aircraft category (SA, 2013).

\begin{tabular}{lllll}
\hline \hline Aircraft category & \multicolumn{2}{l}{ Generation G1 } & \multicolumn{2}{l}{ Generation G2 } \\
\cline { 2 - 5 } & EIS & Period (TR) & EIS & Period (TR) \\
\hline Regional Jet & 2015 & 30 & 2040 & 20 \\
Small/Medium Range Twin & 2015 & 30 & 2025 & 25 \\
Long Range Twin & 2014 & 26 & 2040 & 20 \\
Long Range Quad & 2007 & 20 & 2040 & 20 \\
\hline \hline
\end{tabular}


TABLE V

Noise reductions (EPNdB) at each certification point for each aircraft category in generations G1 and G2 (SA, 2013; Adib et al., 2014).

\begin{tabular}{|c|c|c|c|c|c|c|c|}
\hline \multirow[t]{2}{*}{ Aircraft category } & \multirow[t]{2}{*}{ Reference aircraft } & \multicolumn{3}{|c|}{ Generation G1 } & \multicolumn{3}{|c|}{ Generation G2 } \\
\hline & & Lateral & Flyover & Approach & Lateral & Flyover & Approach \\
\hline Regional Jet & CRJ-900 & 3.80 & 5.30 & 0.60 & 9.97 & 6.47 & 6.27 \\
\hline Small/Medium Range Twin & $737-800$ & 4.30 & 0.00 & 0.00 & 9.43 & 5.40 & 3.33 \\
\hline Long Range Twin & A330 & 3.60 & 6.50 & 1.50 & 14.00 & 7.31 & 7.19 \\
\hline Long Range Quad & $747-400$ & 6.10 & 3.50 & 4.10 & 12.41 & 8.52 & 4.67 \\
\hline
\end{tabular}




\section{TABLE BI}

Change in $90-L_{E}$ contour area for all the conditions evaluated in each of the four aircraft combinations using INM and RANE. In brackets it is shown the relative error (as compared to INM).

\begin{tabular}{|c|c|c|c|}
\hline & & INM & RANE \\
\hline \multirow[t]{3}{*}{ B747400 + CRJ900 } & Sc1 & 0.99 & $1.04(5.28 \%)$ \\
\hline & $\mathrm{Sc} 2$ & 0.09 & $0.09(-0.41 \%)$ \\
\hline & $\mathrm{Sc} 3$ & 1.07 & $1.09(1.84 \%)$ \\
\hline \multirow[t]{3}{*}{$\mathrm{B} 747400+\mathrm{A} 320$} & Sc1 & 0.92 & $0.99(7.50 \%)$ \\
\hline & $\mathrm{Sc} 2$ & 0.15 & $0.13(-7.53 \%)$ \\
\hline & $\mathrm{Sc} 3$ & 1.06 & $1.07(1.59 \%)$ \\
\hline \multirow[t]{3}{*}{$\mathrm{B} 747400+\mathrm{B} 737800$} & Sc1 & 0.83 & $0.86(3.27 \%)$ \\
\hline & $\mathrm{Sc} 2$ & 0.25 & $0.23(-6.93 \%)$ \\
\hline & $\mathrm{Sc} 3$ & 1.06 & $1.05(-0.57 \%)$ \\
\hline \multirow[t]{3}{*}{$\mathrm{B} 747400+\mathrm{A} 330$} & Sc1 & 0.58 & $0.56(-4.19 \%)$ \\
\hline & $\mathrm{Sc} 2$ & 0.38 & $0.40(5.25 \%)$ \\
\hline & $\mathrm{Sc} 3$ & 0.94 & $0.92(-1.65 \%)$ \\
\hline
\end{tabular}




\section{Figure captions}

FIG. 1. Example of a typical aircraft trajectory consisting of straight-line segments. "(color online)"

FIG. 2. Definition of inclination angle $(\gamma)$, segment length $(s)$, segment start $\left(x_{i}\right)$ and end $\left(x_{f}\right)$ points and the noise radius (R). "(color online)"

FIG. 3. Definition of factors for the determination of the limits of integration in noise contour area equation (24), in a flightpath composed of two segments. "(color online)"

FIG. 4. Change in 57dBA-LAeq,d contour area ref to $\mathrm{F}=1$ and error of RANE model as compared to INM for CRJ-900 (a), 737-800 (b), A330 (c) and 747-400 (d) aircraft for an increasing number of operations (from $\mathrm{F}=1.1$ to $\mathrm{F}=3$ ).

FIG. 5. Change in $57 \mathrm{dBA}-\mathrm{L}_{\text {Aeq,d }}$ contour area ref to year 2013 and error of RANE model as compared to INM for 2013 Gatwick airport fleet between the period 2014-2055.

FIG. 6. Departure NPD of aircraft 737-800 with engine CF567B (left), and of the corresponding G2 aircraft with the noise reductions as projected by Adib et al. (2014) (right), for 16000, 19000 and $23500 \mathrm{lbf}$ power-settings.

FIG. 7. Change in 57dBA-LAeq,d contour area and relative number of operations for all UK (ref to year 2010), considering the growth rates projected by (DfT, 2013), the transition rates between current and future aircraft proposed by (SA, 2013) and the noise technology reductions estimated by (SA, 2013; Adib et al., 2014), between the period 2020-2050. 
${ }^{i}$ See supplementary material at [URL will be inserted by AIP] for (1) results of noise contour areas calculated with turning trajectories, (2) data supporting the assumption of equivalence of noise reductions in EPNdB and in $\mathrm{dB}$, and (3) scatter diagrams of $L_{A e q, 16 h}$ calculated using INM and RANE stage 1. 


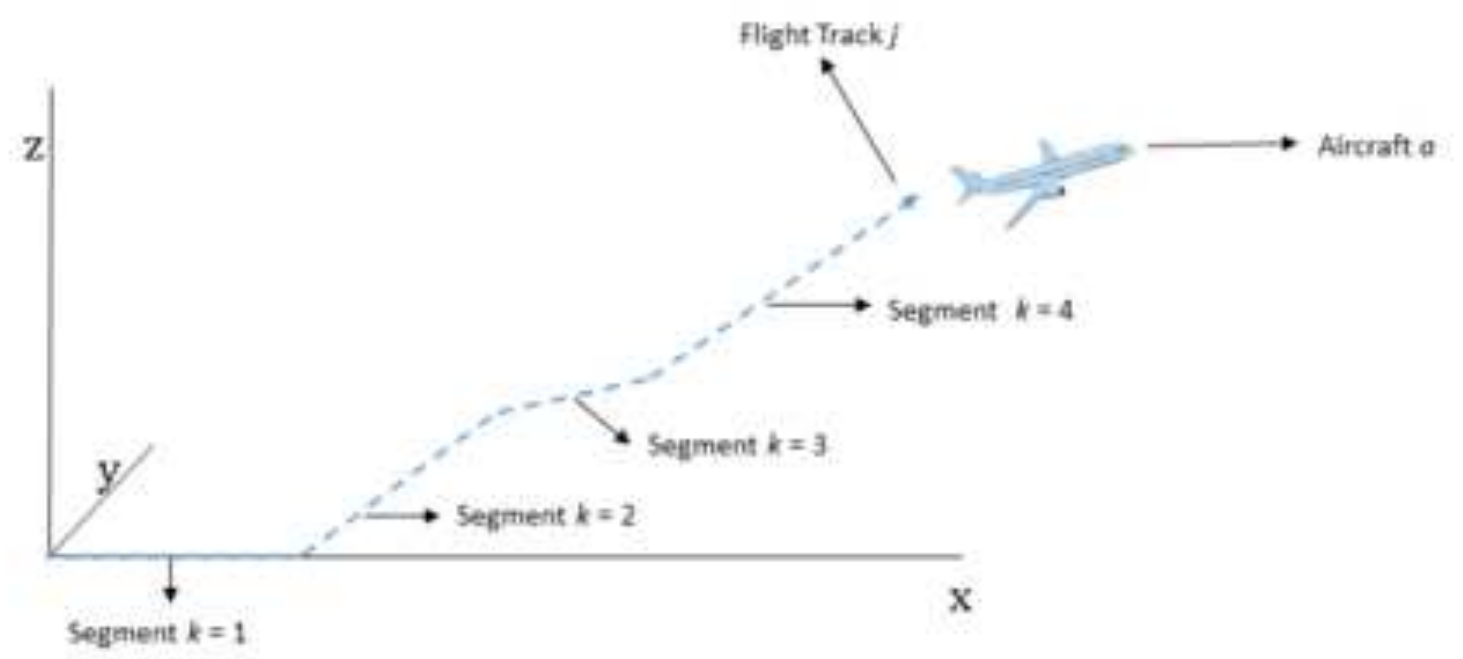




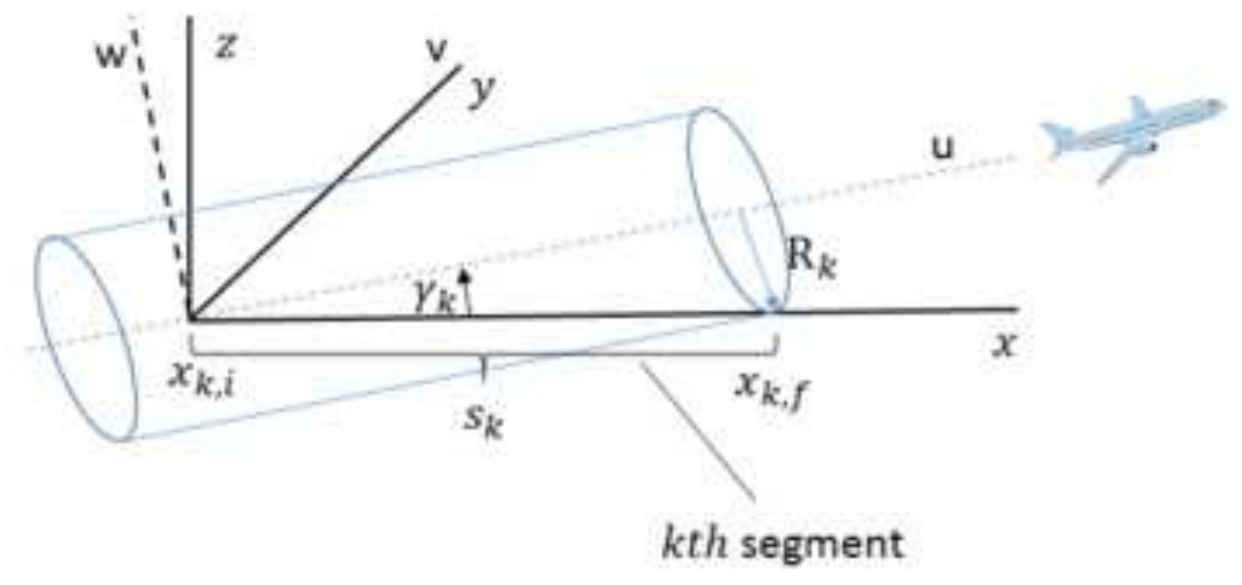




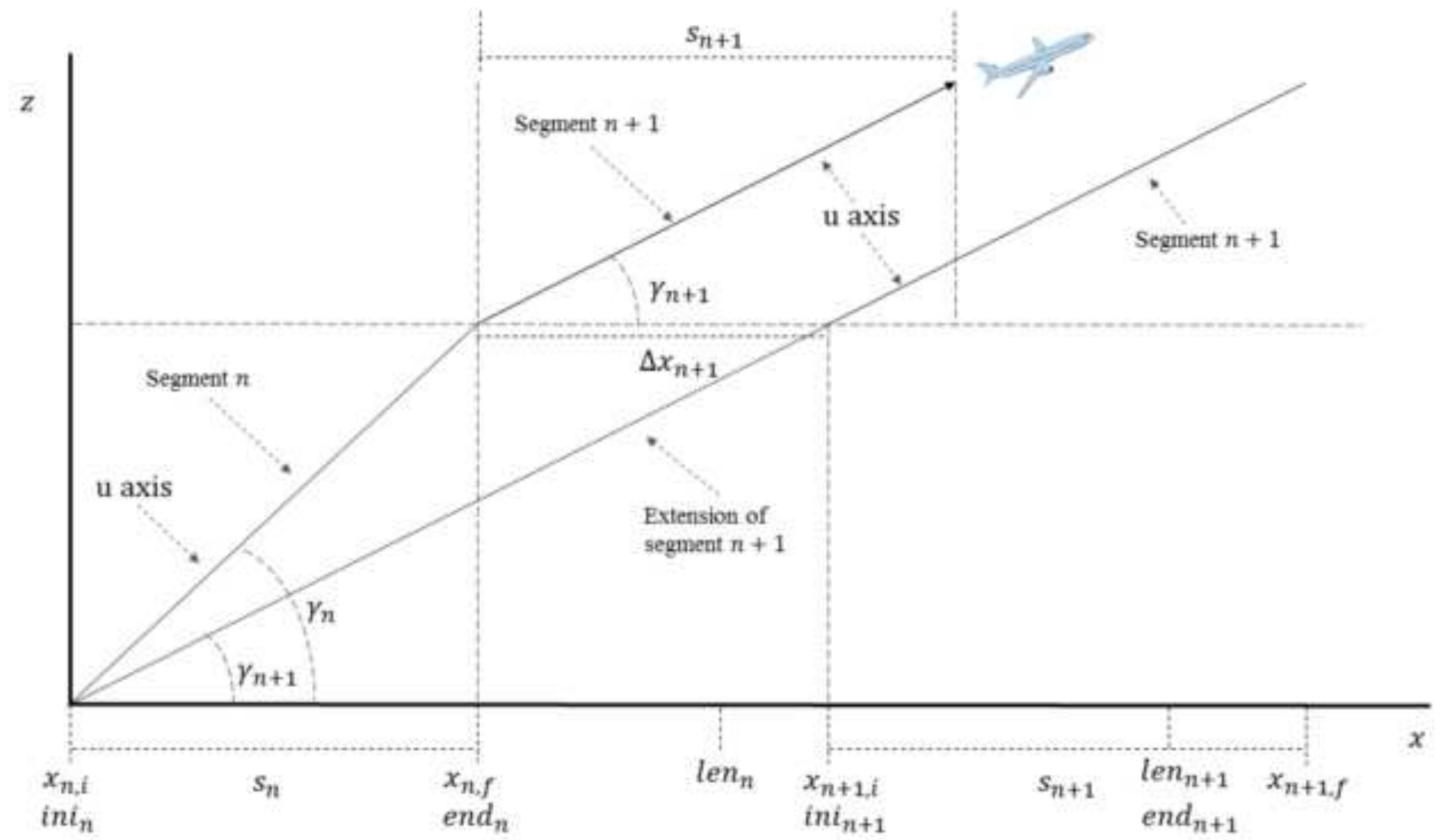



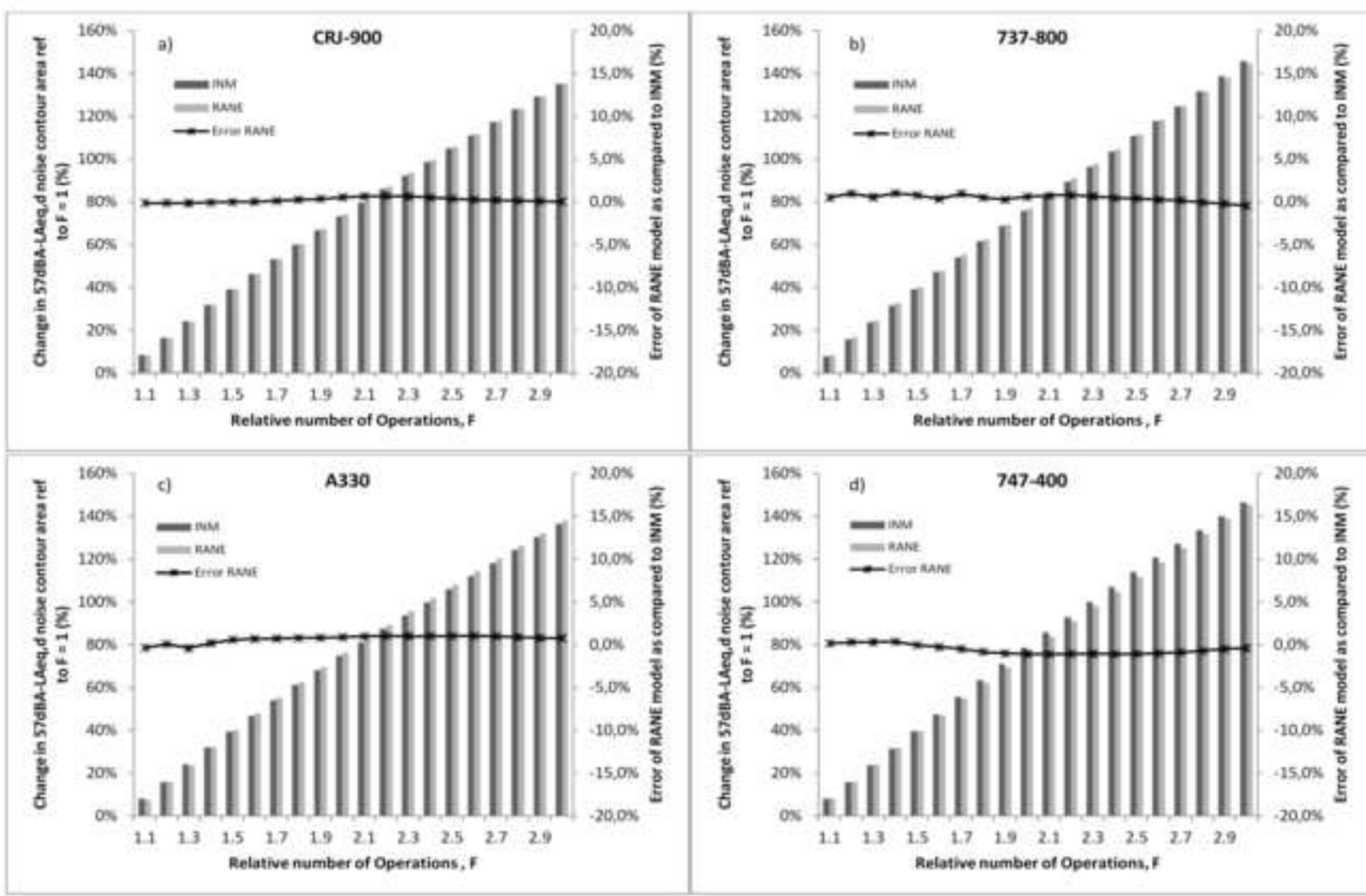


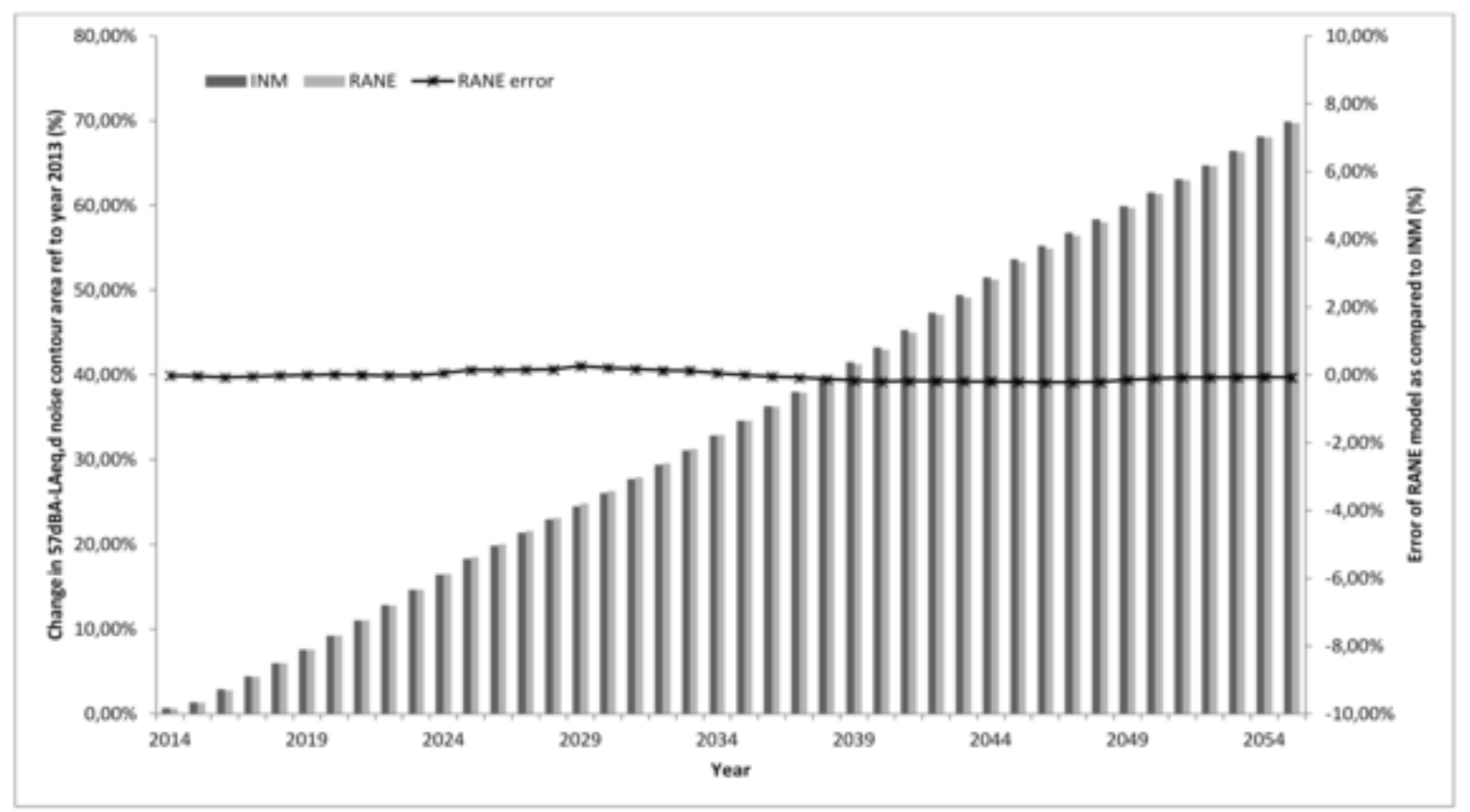




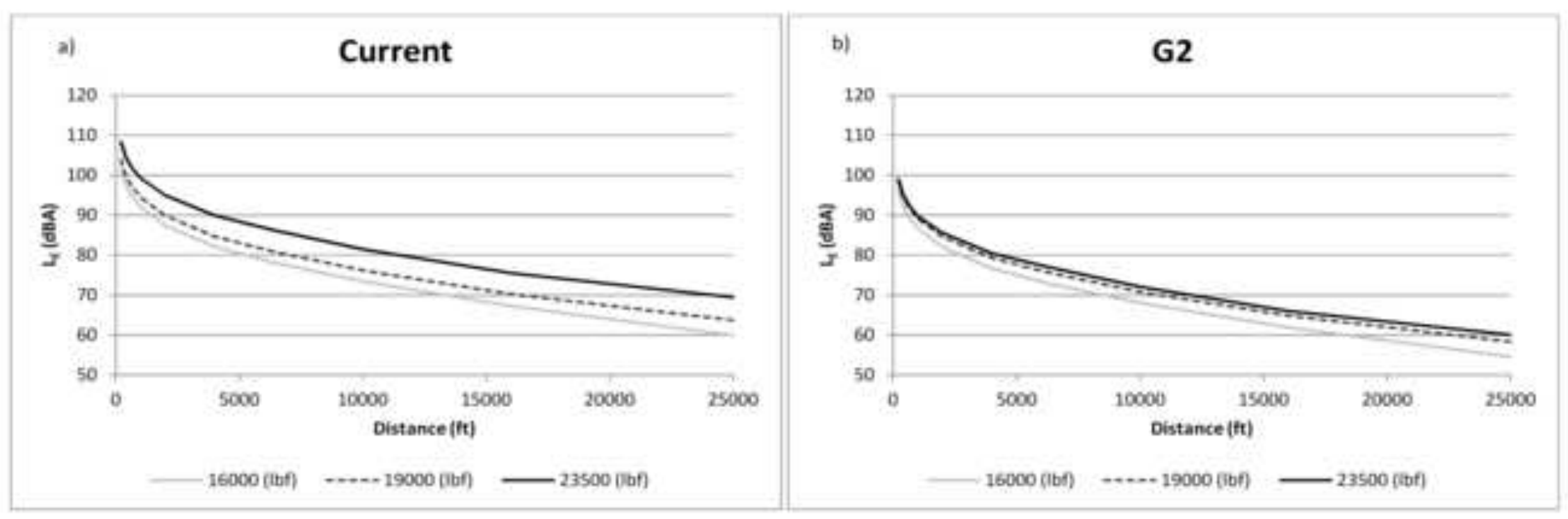




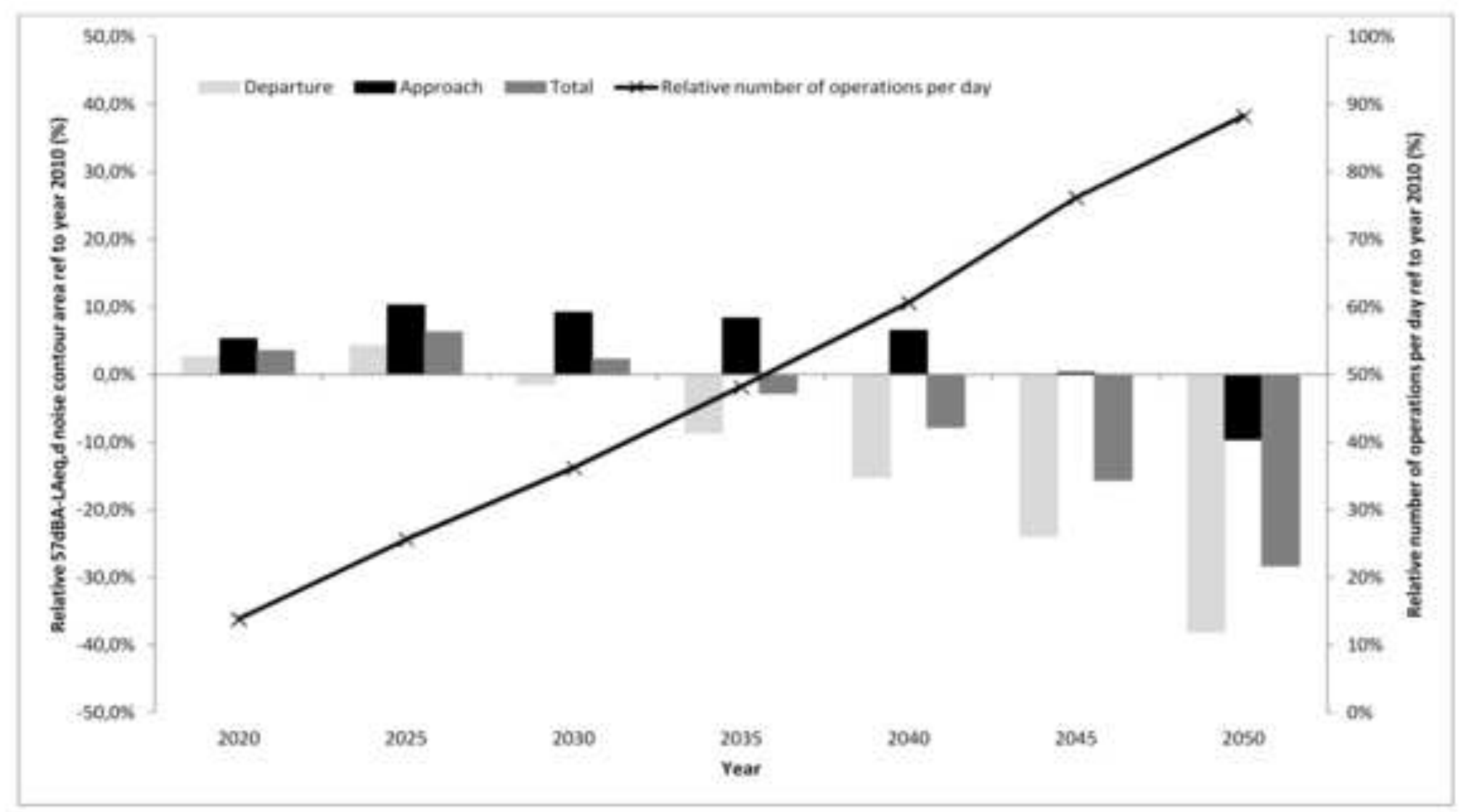




\section{Click here to access/download \\ Supplemental Files for Publication SuppPub1.docx}

